\title{
Global-scale combustion sources of organic aerosols: sensitivity to formation and removal mechanisms
}

\author{
Alexandra P. Tsimpidi ${ }^{1}$, Vlassis A. Karydis ${ }^{1}$, Spyros N. Pandis ${ }^{2,3}$, and Jos Lelieveld ${ }^{1,4}$ \\ ${ }^{1}$ Department of Atmospheric Chemistry, Max Planck Institute for Chemistry, Mainz, Germany \\ ${ }^{2}$ Department of Chemical Engineering, University of Patras, Patras, Greece \\ ${ }^{3}$ Department of Chemical Engineering, Carnegie Mellon University, Pittsburgh, PA, USA \\ ${ }^{4}$ Energy, Environment and Water Research Center, Cyprus Institute, Nicosia, Cyprus \\ Correspondence to: Alexandra P. Tsimpidi (a.tsimpidi@mpic.de)
}

Received: 5 January 2017 - Discussion started: 11 January 2017

Revised: 2 May 2017 - Accepted: 3 May 2017 - Published: 20 June 2017

\begin{abstract}
Organic compounds from combustion sources such as biomass burning and fossil fuel use are major contributors to the global atmospheric load of aerosols. We analyzed the sensitivity of model-predicted global-scale organic aerosols $(\mathrm{OA})$ to parameters that control primary emissions, photochemical aging, and the scavenging efficiency of organic vapors. We used a computationally efficient module for the description of OA composition and evolution in the atmosphere (ORACLE) of the global chemistry-climate model EMAC (ECHAM/MESSy Atmospheric Chemistry). A global dataset of aerosol mass spectrometer (AMS) measurements was used to evaluate simulated primary (POA) and secondary (SOA) OA concentrations. Model results are sensitive to the emission rates of intermediate-volatility organic compounds (IVOCs) and POA. Assuming enhanced reactivity of semi-volatile organic compounds (SVOCs) and IVOCs with $\mathrm{OH}$ substantially improved the model performance for SOA. The use of a hybrid approach for the parameterization of the aging of IVOCs had a small effect on predicted SOA levels. The model performance improved by assuming that freshly emitted organic compounds are relatively hydrophobic and become increasingly hygroscopic due to oxidation.
\end{abstract}

\section{Introduction}

Organic aerosol (OA) is an important constituent of the atmosphere, contributing about $50 \%$ of the total submicron dry aerosol mass (Zhang et al., 2011) with major impacts on human health and climate (IPCC, 2013; Lelieveld et al., 2015).
OA comprises a large number of compounds with a wide range in volatility and oxidation states. The material that is in the particulate phase upon emission is called primary organic aerosol (POA). The co-emitted organic vapors can undergo one or more chemical transformations, which can alter their volatility due to functionalization (reducing their volatility) or fragmentation (increasing their volatility). The oxidation products with lower volatility can be transferred to the particulate phase, forming secondary organic aerosol (SOA).

Several regional-scale modeling studies have accounted for the semi-volatile nature and chemical aging of organic compounds by using the volatility basis set (VBS) approach (Donahue et al., 2006), demonstrating improvements in the accuracy of the predicted concentrations of organic aerosols and their chemical properties (Robinson et al., 2007; Shrivastava et al., 2008; Murphy and Pandis, 2009; Hodzic et al., 2010; Tsimpidi et al., 2010, 2011; Fountoukis et al., 2011, 2014; Li et al., 2011; Bergstrom et al., 2012; Athanasopoulou et al., 2013; Zhang et al., 2013). However, only a few global modeling studies have adopted the VBS approach (Pye and Seinfeld, 2010; Jathar et al., 2011; Jo et al., 2013; Tsimpidi et al., 2014). According to these studies, the modeled global tropospheric burden of POA is $0.03-0.23 \mathrm{Tg}$ and of SOA $1.61-2.77 \mathrm{Tg}$, with semi-volatile (SVOCs) and intermediatevolatility (IVOCs) organic compounds contributing 0.71$1.57 \mathrm{Tg}$ to the total.

The VBS approach is a flexible framework for simulating OA formation and removal; however, there are several uncertainties in the parameters used. The first source of uncertainty is related to the emissions of organic particles and 
vapors (Kanakidou et al., 2005). The volatility distribution of the fresh POA is important in the VBS approach as it determines the initial evaporation of POA. Part of the IVOC emissions is not included in conventional inventories, even if it is important for the predicted SOA (Shrivastava et al., 2008; Grieshop et al., 2009; Tsimpidi et al., 2010). Several studies have assumed a $50 \%$ addition to the traditional emission inventory (e.g., Shrivastava et al., 2008; Jathar et al., 2011; Tsimpidi et al., 2014) for IVOC emissions, but enhancements up to a factor of 6.5 have been used in the literature (e.g., Shrivastava et al., 2011). Furthermore, most previous modeling studies typically assumed the same volatility distributions of all emissions independent of their source (e.g., Robinson et al., 2007). However, recent investigations reported significant differences in the volatility distribution of particles emitted from biomass burning, diesel, and gasoline vehicle exhausts (May et al., 2013a, b, c).

The second source of uncertainty is related to the oxidation of the emitted SVOCs and IVOCs. The parameters used by the VBS approach to simulate this process are the oxidation rate constant, the volatility distribution of the products, and the oxygen mass added per generation of oxidation. The VBS volatility resolution used to represent the SVOC-IVOC volatility range $\left(3.2 \times 10^{-1} \mu \mathrm{g} \mathrm{m}^{-3}<C^{*}<3.2 \times 10^{6} \mu \mathrm{g} \mathrm{m}^{-3}\right)$ affects these parameters as well. A coarse volatility resolution requires a lower effective oxidation rate constant and a more rapid addition of oxygen and reduction in volatility than a finer volatility resolution. A common representation for the oxidation of SVOCs and IVOCs, mainly used by regional models (e.g., Murphy and Pandis, 2009; Tsimpidi et al., 2010, 2011; Fountoukis et al., 2011, 2014; Bergstrom et al., 2012; Athanasopoulou et al., 2013), is based on the work of Robinson et al. (2007) and Shrivastava et al. (2008) and includes nine volatility bins with saturation concentrations ranging from $10^{-2}$ to $10^{6} \mu \mathrm{g} \mathrm{m}^{-3}$, an oxidation rate constant of $4 \times 10^{-11} \mathrm{~cm}^{3}$ molec ${ }^{-1} \mathrm{~s}^{-1}$ based on Atkinson and Arey (2003), a reduction in volatility by 1 order of magnitude after each reaction, and a $7.5 \%$ net increase in mass to account for the added oxygen. This formulation is rather conservative compared to other studies which have assumed a higher reduction in volatility and/or increase in mass. Shrivastava et al. (2011) assumed a $15 \%$ increase in mass due to the added oxygen, while Grieshop et al. (2009) and Hodzic et al. (2010) assumed a $40 \%$ increase in mass and a 2 orders of magnitude reduction in volatility in each reaction step. Pye and Seinfeld (2010) simulated the POA emissions using two SVOCs (with $C^{*}$ equal to 20 and $1646 \mu \mathrm{g} \mathrm{m}^{-3}$ ) and one IVOC $\left(10^{5} \mu \mathrm{g} \mathrm{m}^{-3}\right)$ and used an oxidation rate constant of $2 \times 10^{-11} \mathrm{~cm}^{3} \mathrm{molec}^{-1} \mathrm{~s}^{-1}$, a 2 orders of magnitude reduction in volatility in each reaction, and a $50 \%$ increase in mass per reaction. Shrivastava et al. (2011) used only two surrogate species ( $C^{*}$ equal to $10^{-2}$ and $10^{5} \mu \mathrm{g} \mathrm{m}^{-3}$ ), an oxidation rate constant of $0.57 \times 10^{-11} \mathrm{~cm}^{3} \mathrm{molec}^{-1} \mathrm{~s}^{-1}$, a 7 orders of magnitude reduction in volatility, and a $50 \%$ increase in mass per reaction. Tsimpidi et al. (2014) used a lower resolution VBS scheme with four surrogate species (with $C^{*}$ $10^{-1}, 10^{1}, 10^{3}$, and $10^{5} \mu \mathrm{g} \mathrm{m}^{-3}$ ), an oxidation rate constant of $2 \times 10^{-11} \mathrm{~cm}^{3} \mathrm{molec}^{-1} \mathrm{~s}^{-1}$, a 2 orders of magnitude reduction in volatility, and a $15 \%$ increase in mass per reaction. All of the above schemes should be viewed as parameterizations of the complex reactions that actually take place; the oxidation products can be up to 4 orders of magnitude lower in volatility than the precursor (Kroll and Seinfeld, 2008). To address this limitation, Jathar et al. (2012) developed a hybrid method to represent the formation of SOA from nonspeciated SVOC and IVOC vapors. According to this framework, the first generation of oxidation of SVOCs and IVOCs is parameterized by fitting to SOA data from smog chamber experiments. Subsequently, the generic multigenerational oxidation scheme of Robinson et al. (2007) was used for the subsequent generation steps.

The third source of uncertainty is related to the scavenging efficiency of gas-phase oxidized SVOCs and IVOCs. The water solubility of these organic vapors is largely unknown, and in most OA modeling studies a fixed effective Henry's law constant (e.g., $H=10^{5} \mathrm{M} \mathrm{atm}^{-1}$ ) is used for all organic compounds. However, organic vapors become increasingly more hydrophilic during their atmospheric lifetime. Pye and Seinfeld (2010) treated the freshly emitted gasphase SVOCs as relatively hydrophobic $\left(H=9.5 \mathrm{M} \mathrm{atm}^{-1}\right)$ and their oxidation products as moderately hydrophilic $\left(H=10^{5} \mathrm{M} \mathrm{atm}^{-1}\right)$. Hodzic et al. (2014) argued that Henry's law constants have a strong negative correlation with the saturation vapor pressures and depend on the precursor species, the extent of photochemical processing, and the $\mathrm{NO}_{x}$ levels during the formation.

In this work we use ORACLE, a computationally efficient module for the description of OA composition and evolution in the atmosphere (Tsimpidi et al., 2014), to quantify the impact of the main VBS parameters on the model OA predictions. Our main focus is the formation of OA from anthropogenic combustion and open biomass burning sources. We conducted different tests to study the sensitivity of the model predictions to emissions, photochemical aging, and scavenging efficiency of LVOCs (low-volatility organic compounds), SVOCs, and IVOCs. The results are compared to the reference simulation and aerosol mass spectrometer (AMS) measurements at multiple locations worldwide following Tsimpidi et al. (2016a). Results from these sensitivity tests help identify the major uncertainties of the VBS formulations and give rise to suggestions about potential model improvements.

\section{Reference model description and application}

\subsection{EMAC Model}

The ECHAM/MESSy Atmospheric Chemistry (EMAC) model is a numerical chemistry and climate simulation sys- 
(a) Reference

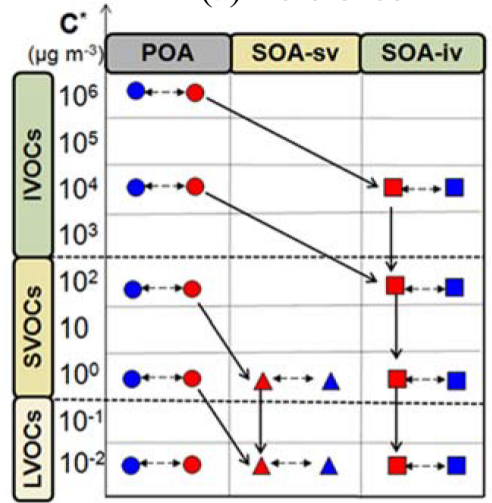

(b) Alternative aging scheme

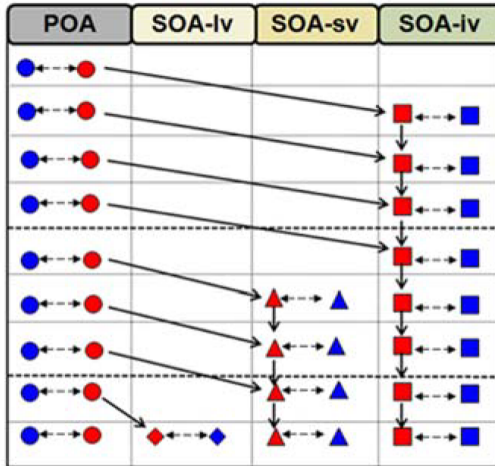

(c) Hybrid aging scheme

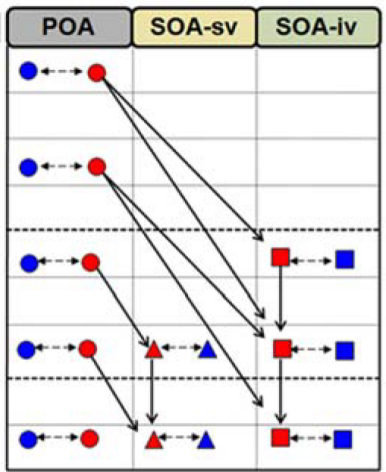

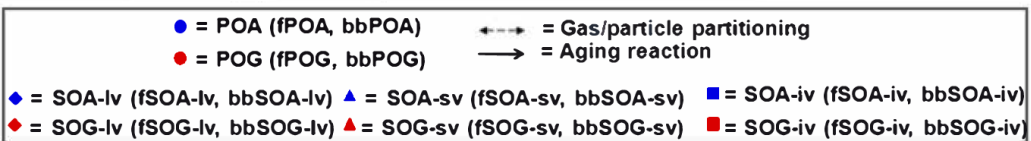

Figure 1. Schematic of the VBS resolution and the formation of SOA from SVOCs and IVOCs in the (a) reference simulation, (b) alternative aging scheme, and (c) hybrid aging scheme. SOA from LVOCs (SOA-lv) is only formed in the alternative aging scheme (b). Red indicates that the organic compound is in the vapor phase and blue in the particulate phase. The circles correspond to primary organics emitted as gases or particles. Diamonds symbolize the formation of SOA from LVOC emissions by fuel combustion and biomass burning. Triangles indicate SOA formation from SVOC emissions by fuel combustion and biomass burning, while the squares show SOA from IVOCs by the same sources. Gas-aerosol partitioning, aging reactions, and names of species are also shown.

tem that includes sub-models describing lower and middle atmosphere processes and their interaction with oceans, land, and human influences (Jöckel et al., 2006). EMAC includes sub-models that describe gas-phase chemistry (MECCA; Sander et al., 2011), inorganic aerosol microphysics (GMXe; Pringle et al., 2010), cloud microphysics (CLOUD; Jöckel et al., 2006), aerosol optical properties (AEROPT; Lauer et al., 2007), dry deposition and sedimentation (DRYDEP and SEDI; Kerkweg et al., 2006a), cloud scavenging (SCAV; Tost et al., 2006), emissions (ONLEM and OFFLEM; Kerkweg et al., 2006b), and organic aerosol formation and growth (ORACLE; Tsimpidi et al., 2014). The EMAC model has been extensively described and evaluated against in situ observations and satellite retrievals (Pozzer et al., 2012; Karydis et al., 2016, 2017; Tsimpidi et al., 2016b). The spectral resolution used in this study is T63L31, corresponding to a horizontal grid spacing of $1.875^{\circ} \times 1.875^{\circ}$ and 31 vertical layers extending to $25 \mathrm{~km}$ altitude. The thickness of the first vertical layer is $68 \mathrm{~m}$. The 11-year period between 2000 and 2010 is simulated, with the 1 st year used as spin-up.

\subsection{ORACLE module}

ORACLE is a computationally efficient sub-model for the description of OA composition and evolution in the atmosphere (Tsimpidi et al., 2014). ORACLE simulates a wide variety of semi-volatile organic products, separating them into bins of logarithmically spaced effective saturation concentrations. In this study, primary organic emissions from biomass burning and fuel combustion sources are taken into account using separate surrogate species for each source category. These surrogates are subdivided into three groups of organic compounds: LVOCs $\left(C^{*}=10^{-2} \mu \mathrm{g} \mathrm{m}^{-3}\right)$, SVOCs $\left(C^{*}=10^{0}\right.$ and $\left.10^{2} \mu \mathrm{g} \mathrm{m}^{-3}\right)$, and IVOCs $\left(C^{*}=10^{4}\right.$ and $\left.10^{6} \mu \mathrm{g} \mathrm{m}^{-3}\right)$. These organic compounds are allowed to partition between the gas and aerosol phases resulting in the formation of POA. Anthropogenic and biogenic VOCs are simulated separately, and their oxidation results in products distributed in four volatility bins with effective saturation concentrations of $10^{0}$, $10^{1}, 10^{2}$, and $10^{3} \mathrm{\mu g} \mathrm{m}^{-3}$. Gas-phase photochemical reactions that modify the volatility of the organics are taken into account, and the oxidation products (SOA-sv, SOA-iv, and SOA-v) of each group of precursors (SVOCs, IVOCs, and VOCs) are simulated separately in the module to keep track of their origin. We have assumed that functionalization and fragmentation processes result in a net average decrease in volatility for SOA produced by SVOC-IVOC and anthropogenic VOC, without a net average change of volatility for SOA produced by biogenic VOCs (Murphy et al., 2012). The volatilities of SVOCs and IVOCs are reduced by a factor of $10^{2}$ as a result of the $\mathrm{OH}$ reaction with a rate constant of $2 \times 10^{-11} \mathrm{~cm}^{3} \mathrm{molec}^{-1} \mathrm{~s}^{-1}$ and a $15 \%$ increase in mass to account for two added oxygen atoms (Tsimpidi et al., 2014). LVOCs are not allowed to participate in photochemical reactions since they are already in the lowest volatility bin. In total 52 organic compounds are simulated explicitly (26 in each of the gas and aerosol phases). The model setup and the different aerosol types and chemical processes that were simulated by ORACLE in this study are illustrated in Fig. 1a. 

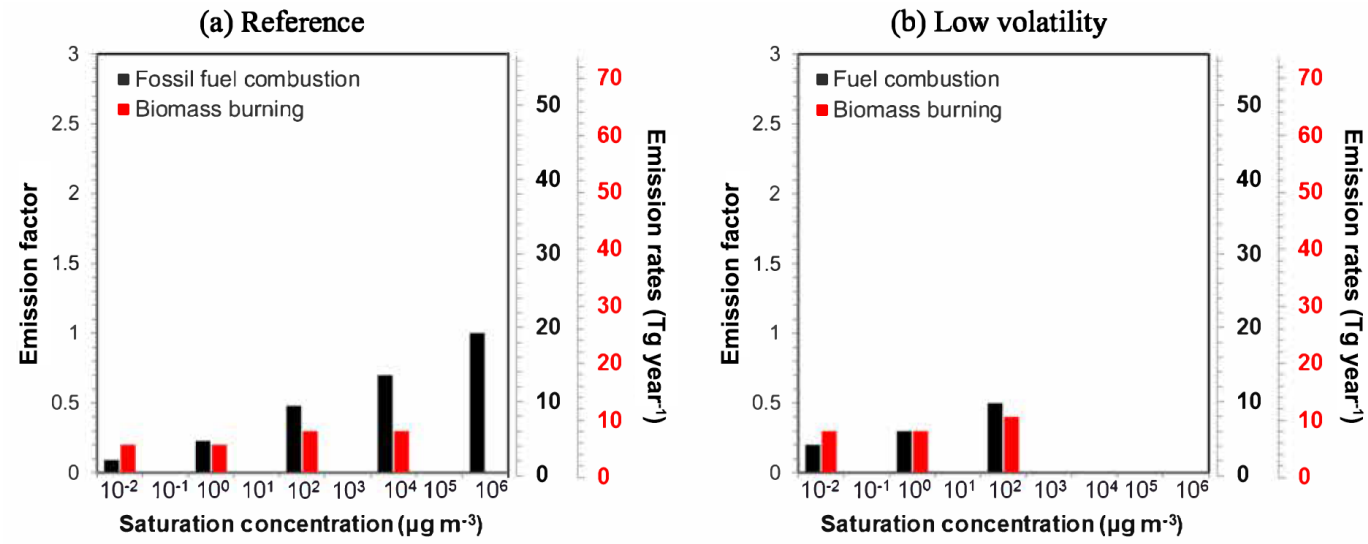

(c) High IVOCs

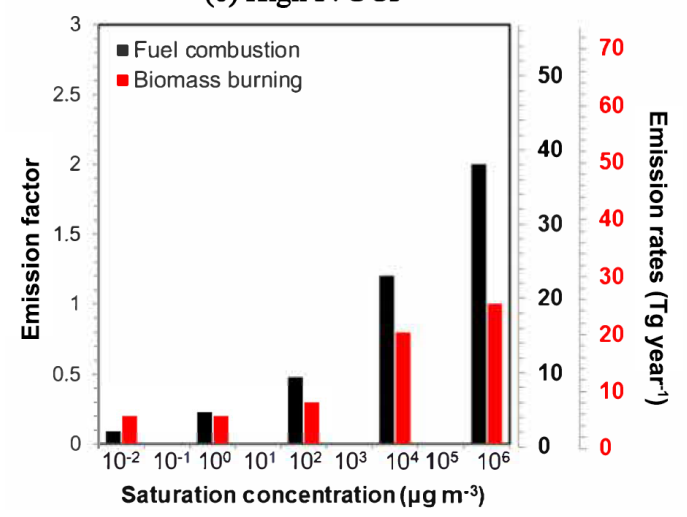

(d) Alternative aging scheme

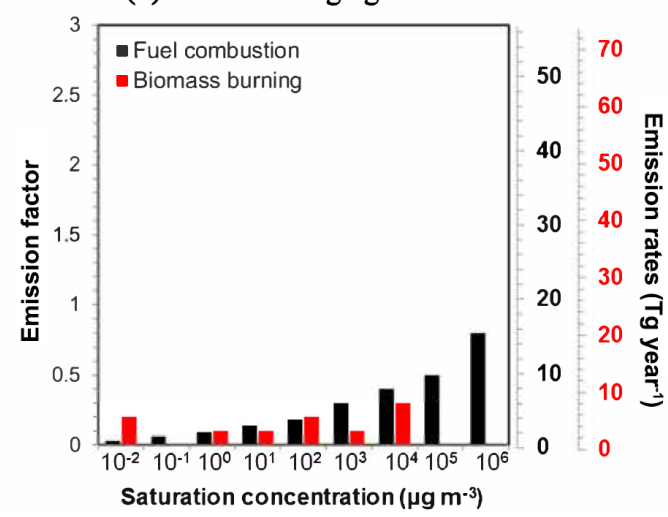

Figure 2. Volatility distribution for fuel combustion (black) and biomass burning OA (red) for the (a) reference, (b) low-volatility, (c) high IVOCs, and (d) alternative aging scheme simulations. The reference emission factors are from Robinson et al. (2007) for $f$ POA (anthropogenic POA from fossil fuel and biofuel combustion) and May et al. (2013) for bbPOA (natural POA from open biomass burning) emissions. The emission rates of $f \mathrm{POA}$ and bbPOA are also shown on the right axis.

More details about ORACLE can be found in Tsimpidi et al. (2014).

\subsection{Emission inventory}

The CMIP5 RCP4.5 emission inventory (Clarke et al., 2007) is used for the anthropogenic POA emissions from fuel combustion and biomass burning. The open biomass burning emissions from savanna and forest fires are based on the Global Fire Emissions Database version 3.1 (GFED v3.1; van der Werf et al., 2010). In order to convert the emitted organic carbon (OC) to organic mass $(\mathrm{OM}), \mathrm{OM} / \mathrm{OC}$ factors of 1.3 and 1.6 have been used for the anthropogenic and biomass burning emissions, respectively (Aiken et al., 2008; Canagaratna et al., 2015). Furthermore, emission fractions are used to distribute the OM to the volatility bins used by ORACLE. The sum of the emission fractions used for the volatility bins with $C^{*} \leq 10^{4}$ is unity, since current emission inventories are based on samples collected at aerosol concentrations up to $10^{4} \mu \mathrm{g} \mathrm{m}^{-3}$ (Shrivastava et al., 2008; Robinson et al., 2010). Additional emission fractions can be assigned to the volatility bins with $C^{*}>10^{4}$ based on dilution experiments (Robinson et al., 2007).

In this study we assume that anthropogenic fuel (fossil and biofuel) combustion emissions cover a range of volatilities from $10^{-2}$ to $10^{6} \mu \mathrm{g} \mathrm{m}^{-3}$ and the additional IVOC emissions are 1.5 times the traditional POA emissions (Robinson et al., 2007); therefore, the sum of the emission fractions for the fuel combustion emissions is 2.5 (Fig. 2a). Biomass burning emissions are assumed to cover a range of volatilities from $10^{-2}$ to $10^{4}$ (May et al., 2013a), and no additional IVOC emissions are assumed from biomass burning sources. Therefore, the sum of their emission factors is unity (Fig. 2a). Overall, the decadal average global emission flux of primary organic emissions is $44 \mathrm{Tg} \mathrm{yr}^{-1}$ from anthropogenic combustion sources and $28 \mathrm{Tg} \mathrm{yr}^{-1}$ from open biomass burning sources.

\section{Sensitivity simulations}

All sensitivity calculations are conducted for the same 11year period as the reference simulation, the results of which 
Table 1. Parameters used in the sensitivity simulations.

\begin{tabular}{|c|c|c|c|c|c|c|c|c|c|c|}
\hline \multirow[t]{2}{*}{$\begin{array}{l}\text { Simulation } \\
\text { name }\end{array}$} & \multicolumn{2}{|c|}{$\begin{array}{l}\text { Emission } \\
\text { factor }\end{array}$} & \multicolumn{2}{|c|}{$\begin{array}{l}\text { Emission } \\
\text { rate } \\
\left(\mathrm{Tg} \mathrm{yr}^{-1}\right)\end{array}$} & \multirow[t]{2}{*}{$\begin{array}{l}\text { Volatility } \\
\text { bins }\end{array}$} & \multirow[t]{2}{*}{$\begin{array}{l}\text { Reduction in } \\
\text { volatility } \\
\left(\mu \mathrm{g} \mathrm{m}^{-3}\right)\end{array}$} & \multirow[t]{2}{*}{$\begin{array}{l}\text { Stoichiometric } \\
\text { coefficient of } \\
\text { aging reactions }\end{array}$} & \multirow[t]{2}{*}{$\begin{array}{c}\text { Oxidation rate } \\
\text { constant } \\
\left(\mathrm{cm}^{3} \mathrm{molec}^{-1} \mathrm{~s}^{-1}\right)\end{array}$} & \multicolumn{2}{|c|}{$\begin{array}{c}\text { Henry's law } \\
\text { constant } \\
\left(\mathrm{mol} \mathrm{L}^{-1} \mathrm{~atm}^{-1}\right)\end{array}$} \\
\hline & $f \mathrm{POA}$ & bbPOA & $f \mathrm{POA}$ & bbPOA & & & & & $\begin{array}{l}\text { Freshly } \\
\text { emitted }\end{array}$ & Aged \\
\hline Reference & 2.5 & 1 & 44.2 & 28.4 & 5 & $10^{2}$ & 1.15 & $2 \times 10^{-11}$ & $10^{5}$ & $10^{5}$ \\
\hline Low volatility & 1 & 1 & 17.7 & 28.4 & 5 & $10^{2}$ & 1.15 & $2 \times 10^{-11}$ & $10^{5}$ & $10^{5}$ \\
\hline High IVOCs & 4 & 2.5 & 70.7 & 71 & 5 & $10^{2}$ & 1.15 & $2 \times 10^{-11}$ & $10^{5}$ & $10^{5}$ \\
\hline $\begin{array}{l}\text { Alternative } \\
\text { POA emissions }\end{array}$ & 2.5 & 1 & 28.5 & 37.8 & 5 & $10^{2}$ & 1.15 & $2 \times 10^{-11}$ & $10^{5}$ & $10^{5}$ \\
\hline $\begin{array}{l}\text { High reaction } \\
\text { rate constant }\end{array}$ & 2.5 & 1 & 44.2 & 28.4 & 5 & $10^{2}$ & 1.15 & $4 \times 10^{-11}$ & $10^{5}$ & $10^{5}$ \\
\hline $\begin{array}{l}\text { Alternative } \\
\text { aging scheme }\end{array}$ & 2.5 & 1 & 44.2 & 28.4 & 9 & 10 & 1.075 & $4 \times 10^{-11}$ & $10^{5}$ & $10^{5}$ \\
\hline $\begin{array}{l}\text { Hybrid aging } \\
\text { scheme }\end{array}$ & 2.5 & 1 & 44.2 & 28.4 & 5 & $\begin{array}{c}\text { SVOCs : } 10^{2} \\
\text { IVOCs : } 10^{4}-10^{6}\end{array}$ & $\begin{array}{c}\text { SVOCs : } 1.15 \\
\text { IVOCs : } 1.115-0.71\end{array}$ & $\begin{array}{l}\text { SVOCs : } 2 \times 10^{-11} \\
\text { IVOCs : } 1.2 \times 10^{-11}\end{array}$ & $10^{5}$ & $10^{5}$ \\
\hline Low solubility & 2.5 & 1 & 44.2 & 28.4 & 5 & $10^{2}$ & 1.15 & $2 \times 10^{-11}$ & $10^{3}$ & $10^{3}$ \\
\hline Variable solubility & 2.5 & 1 & 44.2 & 28.4 & 5 & $10^{2}$ & 1.15 & $2 \times 10^{-11}$ & 10 & $10^{5}$ \\
\hline
\end{tabular}

have been analyzed by Tsimpidi et al. (2016a). Table 1 summarizes the general characteristics of the sensitivity simulations. A detailed description is provided below.

\subsection{Sensitivities to emissions}

The emissions of LVOCs, SVOCs, and IVOCs are a key input for the accurate description of atmospheric OA. To quantify the sensitivity of the reference case results to the LVOC, SVOC, and IVOC emissions, three simulation tests have been designed. Figure 2 summarizes the emission factors used for the volatility distribution of the emissions, the emission rate of each volatility bin for the reference simulation, and the sensitivity tests. These are more specifically described in the following.

Low volatility: in this sensitivity simulation, we assume zero emissions of IVOCs to quantify their contribution to the formation of global SOA. Therefore, the fuel combustion and biomass burning emissions are distributed only in the LVOC $\left(10^{-2} \mu \mathrm{g} \mathrm{m}^{-3}\right)$ and SVOC $\left(10^{0}\right.$ and $\left.10^{2} \mu \mathrm{g} \mathrm{m}^{-3}\right)$ volatility bins, and the sum of their emission fractions is equal to unity (Fig. 2b). The decadal average global emission flux of primary organic emissions in this test is $18 \mathrm{Tg} \mathrm{yr}^{-1}$ from anthropogenic combustion sources and $28 \mathrm{Tg} \mathrm{yr}^{-1}$ from open biomass burning sources (Table 1).

High IVOCs: to estimate an upper limit of the IVOC contribution to the formation of SOA, a sensitivity simulation is conducted in which the emissions of IVOCs are increased by 1.5 times the original POA emissions. These emissions are distributed in the volatility bins with $C^{*}$ of $10^{4}$ and $10^{6} \mathrm{\mu g} \mathrm{m}^{-3}$ (Fig. 2c) by applying an additional emission factor of 0.5 and 1, respectively. The LVOC and SVOC emissions are the same as in the reference simulation. Overall, the total anthropogenic and biomass burning emissions are 4 and 2.5 times higher, respectively, than the original POA emission inventory. The decadal average global emission flux of primary organic emissions in this sensitivity test is $71 \mathrm{Tg} \mathrm{yr}^{-1}$ for both anthropogenic and open biomass burning sources (Table 1).

Alternative POA emissions: to investigate the sensitivity of the model results to the magnitude of the POA emissions, we have utilized the AEROCOM database for the POA emissions from anthropogenic combustion sources (Dentener et al., 2006) and the CMIP5 RCP4.5 emission inventory for the POA emissions from open biomass burning sources. These emission inventories include $36 \%$ lower POA emissions from anthropogenic combustion sources and $33 \%$ higher POA emissions from open biomass burning sources on average over the 2000-2010 decade compared to the reference simulation. The assumed volatility distributions are the same as in the reference simulation. The decadal average global emission flux of primary organic emissions in this case is $29 \mathrm{Tg} \mathrm{yr}^{-1}$ from anthropogenic combustion sources and $38 \mathrm{Tg} \mathrm{yr}^{-1}$ from open biomass burning sources (Table 1).

\subsection{Sensitivity to chemistry}

The photooxidation of SVOCs and IVOCs emitted from fuel combustion and biomass burning sources can lead to the formation of substantial SOA mass on a global scale (Jathar et al., 2011; Tsimpidi et al., 2014). To evaluate the sensitivity of the model to the parameters used to describe the aging process, we have conducted three sensitivity simulations described below.

High reaction rate constant: in this simulation we investigate the sensitivity of the results to the rate constant used for the gas-phase photooxidation of SVOCs and IVOCs with $\mathrm{OH}$. We assume that the corresponding oxidation rate constant is twice that of the reference simulation and equal to $4 \times 10^{-11} \mathrm{~cm}^{3} \mathrm{molec}^{-1} \mathrm{~s}^{-1}$. All other parameters remained the same as in the reference simulation (Table 1). 
(a) Total OA

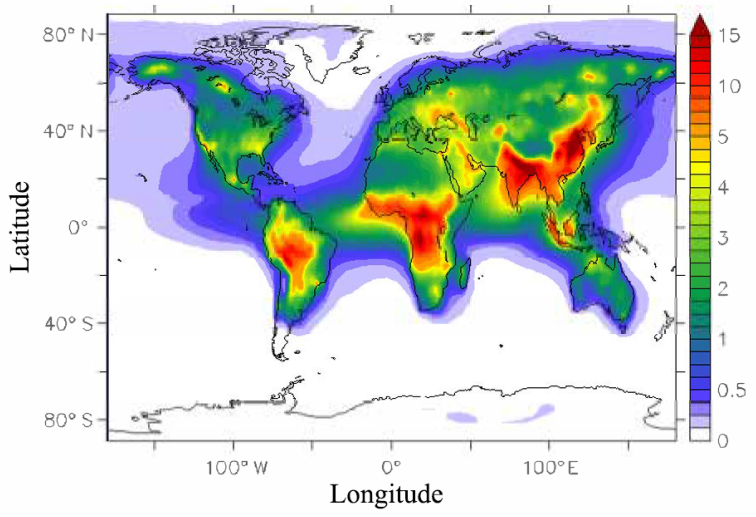

(c) SOA-sv

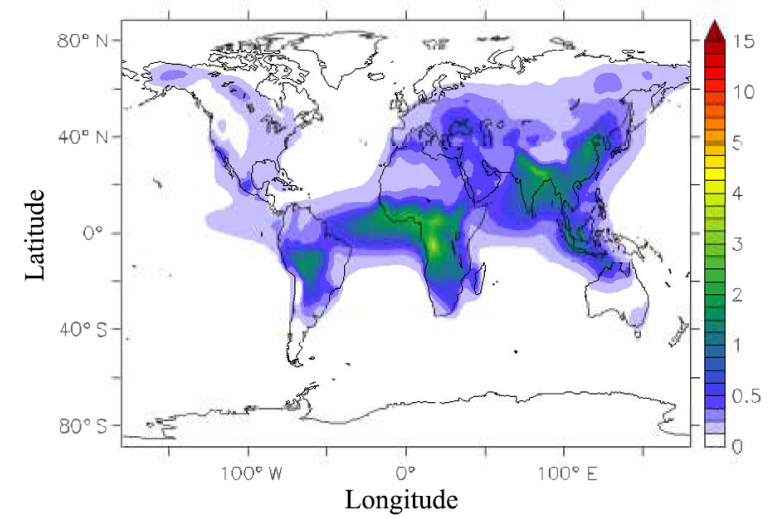

(b) POA

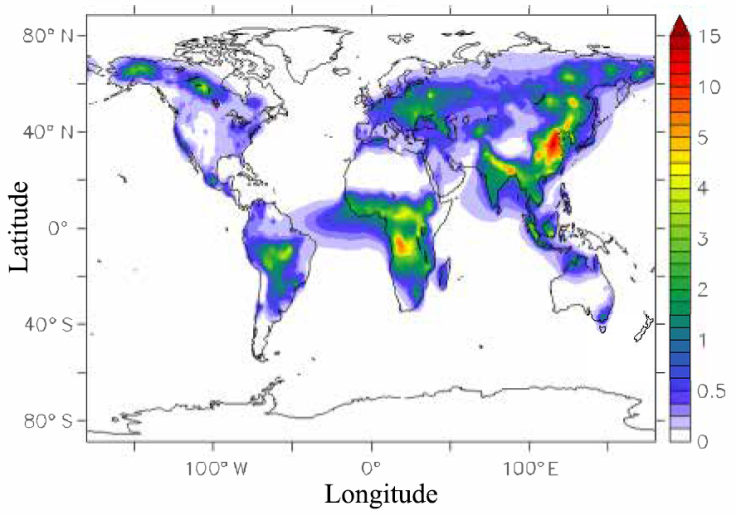

(d) SOA-iv

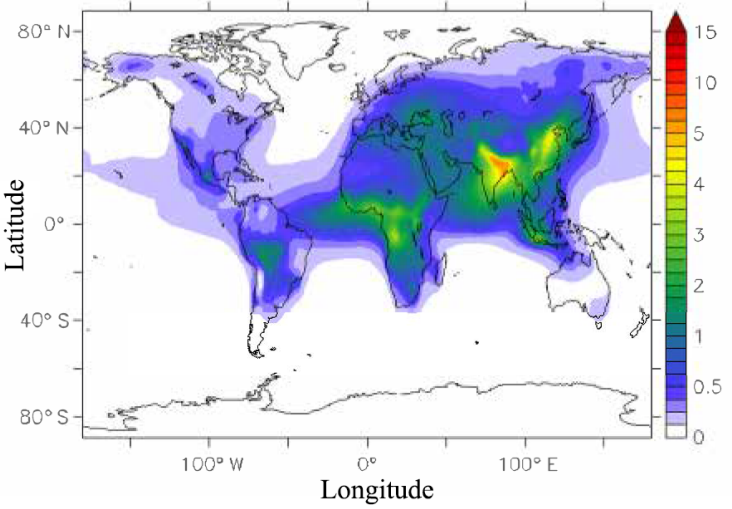

Figure 3. Predicted average surface concentrations (in $\mu \mathrm{g} \mathrm{m}^{-3}$ ) of (a) total OA (sum of POA, SOA-sv, SOA-iv, and SOA-v), (b) POA and (c) SOA from the oxidation of SVOCs (SOA-sv), and (d) SOA from the oxidation of IVOCs (SOA-iv) for the reference simulation during the 2001-2010 period.

Alternative aging scheme: to quantify the sensitivity of the results to the aging scheme, we designed a sensitivity case in which the aging scheme of Robinson et al. (2007) is used (Fig. 1b). Based on this implementation, we are using nine volatility bins (compared to five in the reference simulation) to distribute the primary emissions into LVOCs $\left(10^{-2}\right.$ and $\left.10^{-1} \mu \mathrm{g} \mathrm{m}^{-3}\right)$, SVOCs $\left(10^{0}, 10^{1}\right.$, and $\left.10^{2} \mu \mathrm{g} \mathrm{m}^{-3}\right)$, and IVOCs $\left(10^{3}, 10^{4}, 10^{5}\right.$, and $\left.10^{6} \mu \mathrm{g} \mathrm{m}^{-3}\right)$. This model set up is based on the formulation proposed by Shrivastava et al. (2008). The volatility distribution of anthropogenic combustion and open biomass burning emissions is shown in Fig. 2d. The sum of these emission factors is the same as in the reference simulation ( 2.5 for fuel combustion and 1 for biomass burning). However, the relative importance of SVOCs and IVOCs to total OA emissions is changed compared to the reference simulation. In the sensitivity simulation the fraction of SVOCs to the total emissions is $20 \%$ for $f$ OA (anthropogenic OA from fossil fuel and biofuel combustion) and $60 \%$ for bbOA (natural OA form open biomass burning; Fig. 2d), compared to 32 and $70 \%$, respectively, in the reference simulation (Fig. 2a). Furthermore, the saturation con- centration of the organic vapors reacting with $\mathrm{OH}$ is reduced by a factor of 10 (instead of 100 in the reference simulation), with a rate constant of $4 \times 10^{-11} \mathrm{~cm}^{3} \mathrm{molec}^{-1}$ (double the value used in the reference simulation) and a $7.5 \%$ increase in mass to account for one added oxygen (half the value used in the reference simulation). The formation of SOA from LVOCs is possible in this configuration (contrary to the reference simulation) due to the presence of two species in the LVOC volatility range $\left(C^{*}<3.2 \times 10^{-1} \mu \mathrm{g} \mathrm{m}^{-} 3\right)$. Overall, in this simulation, 46 surrogate OA species are used to track the source- and volatility-resolved OA components compared to 26 aerosol species in the reference simulation.

Hybrid aging scheme: the reference and alternative aging scheme simulations assume that the volatility of the organic vapor precursors is reduced by 2 and 1 orders of magnitude, respectively, after each oxidation step. However, photooxidation reactions of IVOCs can create products with a volatility 1 to 4 orders of magnitude lower (Kroll and Seinfeld, 2008). Furthermore, recent experiments indicate that the reduction in volatility due to oxidation reactions changes as the organic molecules become more oxygenated and frag- 
mentation becomes important (Chacon-Madrid et al., 2013). To investigate the effect of these assumptions on the predicted global SOA burden, we have modified the OA chemistry mechanism to include a hybrid method to calculate the SOA formation from the oxidation of IVOCs based on the approach of Jathar et al. (2012). The SVOC oxidation scheme remains the same as in the reference simulation. The hybrid aging scheme distributes the IVOC first generation oxidation products over a range of volatilities, with larger reductions in volatility compared to the reference simulation. The oxidation of each IVOC is assumed to result in the formation of two condensable organic gases with 4 and 6 orders of magnitude lower volatility and aerosol yields equal to 0.71 and 0.115 , respectively (Jathar et al., 2014) (Fig. 1c). Then, the reference oxidation scheme is used for subsequent oxidation of these products assuming a factor of 100 reduction in volatility with a $15 \%$ increase in mass. The photooxidation of SVOCs and IVOCs in the hybrid aging scheme is described by the following reactions:

$$
\begin{aligned}
& \mathrm{SVOC}_{i}+\mathrm{OH} \rightarrow 1.15 \mathrm{SOG}_{-\mathrm{Sv}_{i-1}}, \\
& \text { SOG-sv }_{i}+\mathrm{OH} \rightarrow 1.15 \mathrm{SOG}^{-\mathrm{sv}_{i-1}} \text {, } \\
& \text { SOG-sv } i \leftrightarrow \text { SOA-sv }_{i} \\
& \text { IVOC }_{i}+\mathrm{OH} \rightarrow 0.71 \text { SOG-iv }_{i-2}+0.115 \text { SOG-iv }_{i-3} \text {, } \\
& \text { SOG-iv }_{i}+\mathrm{OH} \rightarrow 1.15 \mathrm{SOG}^{-i v_{i-1}}, \\
& \text { SOG-iv }_{i} \leftrightarrow \text { SOA-iv }_{i}
\end{aligned}
$$

where $i$ is the original volatility bin and $i-1, i-2$, and $i-3$, are the volatility bins with saturation concentrations reduced by a factor of $10^{2}, 10^{4}$, and $10^{6}$, respectively. The term SOG corresponds to secondary organic gas. This representation is more consistent with SOA formation from VOCs and provides in principle at least a more realistic representation of SOA formation from IVOCs.

\subsection{Sensitivities to scavenging}

The wet and dry removal of the organic vapors from the atmosphere depends on their ability to partition into water which is commonly expressed by their Henry's law constant $(H)$. Two sensitivity simulations where performed to investigate the effect of this uncertain parameter.

Low solubility: to test the sensitivity of the results to the solubility of the SVOC and IVOC vapors, we have conducted a simulation using a Henry's law constant 2 orders of magnitude lower than the reference simulation and equal to $10^{3} \mathrm{M} \mathrm{atm}^{-1}$ for both primary and secondary SVOCs and IVOCs.

Variable solubility: the photochemical aging of organic vapors results on average in less volatile and more hydrophilic products (Jimenez et al., 2009). To quantify the effect of this change on the model results, we have conducted a sensitivity simulation in which the fresh SVOCs and IVOCs are hydrophobic with $H=10 \mathrm{M} \mathrm{atm}^{-1}$ and become more hy- drophilic after their photochemical oxidation with an $H=$ $10^{5} \mathrm{M} \mathrm{atm}^{-1}$.

\section{Reference simulation results and evaluation}

The predicted decadal average surface concentrations of total OA, POA, SOA-sv, and SOA-iv for the reference simulation are shown in Fig. 3. High POA concentrations are predicted over regions affected by biomass burning (i.e., the tropical and boreal forests) as well as over the industrialized regions of the Northern Hemisphere where strong fossil and biofuel combustion sources are located (i.e., eastern and southern Asia, central and eastern Europe, and the western and eastern US). Further downwind of the sources, the POA concentration decreases substantially due to dilution and evaporation (Fig. 3b). On the other hand, the predicted SOA-sv and SOAiv concentrations are high over a wide area downwind of the polluted urban areas and the major rainforests (Fig. 3c, d) due to the transport of IVOCs and SVOCs and their continued chemical transformations. Since IVOC emissions from anthropogenic sources are assumed to be 2 times higher than SVOC emissions (Fig. 1a), the predicted SOA-iv is higher than SOA-sv over populated areas (Fig. 3c, d). On the other hand, over the tropical rainforests, SOA-sv and SOA-iv concentrations are similar due to the low fraction of IVOCs assumed for the open biomass burning OA emissions. Overall, the reference simulation yields a tropospheric OA burden of $1.98 \mathrm{Tg}$ consisting of $12 \% \mathrm{POA}, 18 \%$ SOA-sv, $32 \%$ SOAiv, and $38 \%$ SOA-v. More details about the reference case results can be found in Tsimpidi et al. (2016).

A comprehensive AMS dataset from field campaigns performed in the Northern Hemisphere during 2001-2010 (Tsimpidi et al., 2016) has been used to evaluate the model performance for each simulation. The mean bias (MB), mean absolute gross error (MAGE), normalized mean bias (NMB), normalized mean error (NME), and the root mean square error (RMSE) are used to assess the model performance for POA (versus AMS hydrocarbon-like aerosol, HOA; Table 2) and SOA (versus AMS oxygenated organic aerosol, OOA; Table 3). Tsimpidi et al. (2016) have shown that, as expected, the model underestimates the concentrations of POA and SOA over urban locations due to its coarse resolution and missing sources in the emission database (e.g., cold vehicle start and wood burning emissions in winter). Therefore, urban locations are excluded from our analysis in order to avoid misinterpretation of the sensitivity results and their effects on OA model performance. A comprehensive analysis of the model evaluation based on the reference scenario results can be found in Tsimpidi et al. (2016) and will be used here as a reference for analyzing the effect of each sensitivity scenario on the performance of the model. EMAC reproduces POA levels with very little bias ( $\mathrm{NMB}=-3 \%$; Table 2). On the other hand, OOA concentrations are underpredicted $(-31 \%$; Table 3), indicating that the model may be missing an im- 
Table 2. Statistical evaluation of EMAC POA (sum of $f$ POA and bbPOA) against AMS POA (sum of HOA and bbOA) using 61 datasets in urban-downwind and rural areas during 2001-2010.

\begin{tabular}{|c|c|c|c|c|c|c|c|}
\hline $\begin{array}{l}\text { Simulation } \\
\text { name }\end{array}$ & $\begin{array}{r}\text { Mean } \\
\text { observed } \\
\left(\mu g \mathrm{~m}^{-3}\right)\end{array}$ & $\begin{array}{r}\text { Mean } \\
\text { predicted } \\
\left(\mu \mathrm{g} \mathrm{m}^{-3}\right)\end{array}$ & $\begin{array}{l}\text { MAGE } \\
\left(\mu \mathrm{g} \mathrm{m}^{-3}\right)\end{array}$ & $\begin{array}{r}\mathrm{MB} \\
\left(\mu \mathrm{g} \mathrm{m}^{-3}\right)\end{array}$ & $\begin{array}{l}\text { NME } \\
(\%)\end{array}$ & $\begin{array}{l}\text { NMB } \\
(\%)\end{array}$ & $\begin{array}{r}\text { RMSE } \\
\left(\mu \mathrm{g} \mathrm{m}^{-3}\right)\end{array}$ \\
\hline Reference & 0.53 & 0.51 & 0.38 & -0.02 & 71 & -3 & 0.50 \\
\hline Low volatility & & 0.75 & 0.46 & 0.22 & 88 & 43 & 0.64 \\
\hline High IVOCs & & 0.52 & 0.38 & -0.01 & 73 & 0 & 0.51 \\
\hline Alternative & & 0.39 & 0.33 & -0.14 & 63 & -25 & 0.44 \\
\hline $\begin{array}{l}\text { POA emissions } \\
\text { High reaction } \\
\text { rate constant }\end{array}$ & & 0.50 & 0.37 & -0.03 & 70 & -5 & 0.49 \\
\hline $\begin{array}{l}\text { Alternative aging } \\
\text { scheme }\end{array}$ & & 0.17 & 0.42 & -0.36 & 79 & -67 & 0.60 \\
\hline $\begin{array}{l}\text { Hybrid aging } \\
\text { scheme }\end{array}$ & & 0.50 & 0.38 & -0.03 & 72 & -4 & 0.50 \\
\hline Low solubility & & 0.53 & 0.38 & 0 & 72 & 1 & 0.50 \\
\hline Variable solubility & & 0.54 & 0.38 & 0.01 & 73 & 4 & 0.51 \\
\hline
\end{tabular}

Table 3. Statistical evaluation of EMAC SOA against AMS OOA using 61 datasets in downwind urban and rural areas during 2001-2010.

\begin{tabular}{|c|c|c|c|c|c|c|c|}
\hline $\begin{array}{l}\text { Simulation } \\
\text { name }\end{array}$ & $\begin{array}{r}\text { Mean } \\
\text { observed } \\
\left(\mu \mathrm{g} \mathrm{m}^{-3}\right)\end{array}$ & $\begin{array}{r}\text { Mean } \\
\text { predicted } \\
\left(\mu \mathrm{g} \mathrm{m}^{-3}\right)\end{array}$ & $\begin{array}{r}\text { MAGE } \\
\left(\mu \mathrm{g} \mathrm{m}^{-3}\right)\end{array}$ & $\begin{array}{r}\text { MB } \\
\left(\mu \mathrm{g} \mathrm{m}^{-3}\right)\end{array}$ & $\begin{array}{l}\text { NME } \\
(\%)\end{array}$ & $\begin{array}{l}\text { NMB } \\
(\%)\end{array}$ & $\begin{array}{r}\text { RMSE } \\
\left(\mu \mathrm{g} \mathrm{m}^{-3}\right)\end{array}$ \\
\hline Reference & 2.78 & 1.91 & 1.39 & -0.87 & 50 & -31 & 2.02 \\
\hline Low volatility & & 1.32 & 1.69 & -1.46 & 61 & -52 & 2.30 \\
\hline High IVOCs & & 2.50 & 1.47 & -0.28 & 53 & -10 & 2.05 \\
\hline Alternative & & 1.66 & 1.55 & -1.12 & 56 & -40 & 2.15 \\
\hline $\begin{array}{l}\text { POA emissions } \\
\text { High reaction } \\
\text { rate constant }\end{array}$ & & 2.16 & 1.32 & -0.62 & 48 & -22 & 1.97 \\
\hline $\begin{array}{l}\text { Alternative aging } \\
\text { scheme }\end{array}$ & & 1.73 & 1.49 & -1.05 & 53 & -38 & 2.09 \\
\hline $\begin{array}{l}\text { Hybrid aging } \\
\text { scheme }\end{array}$ & & 1.71 & 1.46 & -1.08 & 53 & -39 & 2.08 \\
\hline Low solubility & & 2.10 & 1.33 & -0.68 & 48 & -25 & 1.98 \\
\hline Variable solubility & & 2.14 & 1.32 & -0.64 & 48 & -23 & 1.97 \\
\hline
\end{tabular}

portant source or formation pathway of SOA especially in winter (Tsimpidi et al., 2016) or may be removing the corresponding pollutants faster. Another possible reason for the underprediction of OOA is the uncertainty in SOA yields due to wall losses in laboratory chambers. Zhang et al. (2014) demonstrated that while the particle losses are routinely accounted for, losses of semi-volatile vapors are not well evaluated and can lead to substantial underestimations of the SOA formation.

\section{Sensitivity to emission factors}

\subsection{Low volatility}

In the first sensitivity test, the IVOC emissions are set to zero and only semi-volatile organic compounds are emitted. This is accompanied by an increase in SVOC emissions from anthropogenic and open biomass burning sources by 100 and $40 \%$, respectively. This initial partitioning of the emissions favors the particulate phase, resulting in an increase in POA compared to the reference scenario (Fig. 4a). The largest $f \mathrm{POA}$ and bbPOA increases are predicted over eastern China $\left(4.3 \mu \mathrm{g} \mathrm{m}^{-3}\right)$ and the Congo Basin $\left(3.9 \mu \mathrm{g} \mathrm{m}^{-3}\right)$, respectively. The higher SVOC emissions in the sensitivity simulation result in an increase in the simulated SOA-sv concentrations as well (Fig. 5a). However, since a large fraction of the emitted 
SVOCs remains in the particle phase, the SOA-sv concentration increase is smaller than the corresponding changes in POA. Relatively strong $f$ SOA-sv and bbSOA-sv increases are found over the Indo-Gangetic Plane (IGP) $\left(0.4 \mu \mathrm{g} \mathrm{m}^{-3}\right)$ and the Congo Basin $\left(1.3 \mu \mathrm{g} \mathrm{m}^{-3}\right)$, respectively. The "lowvolatility" simulation does not predict any SOA-iv as it assumes zero IVOC emissions. Therefore, SOA-iv concentrations are zero around the globe, resulting in substantial decreases in areas where the reference simulation predicts high SOA-iv levels (Figs. 3d, c and 6a).

The significant decrease in organic emissions from anthropogenic sources (Table 1) due to the lack of IVOC emissions results in an overall decrease in total OA concentrations by up to $5 \mu \mathrm{g} \mathrm{m}^{-3}$ over anthropogenically polluted regions (Fig. 7a). On the other hand, organic emissions from open biomass burning sources remain at the same level as the reference simulation (Table 1); however, they are assumed to have lower volatility. This results in an increase in total OA concentrations in the sensitivity simulation by up to $2 \mu \mathrm{g} \mathrm{m}^{-3}$ over the tropical and boreal forests. Overall, the calculated tropospheric burden of POA in the sensitivity simulation increases by around $50 \%$ due to the increase in the SVOC emissions (Table 2). For the same reason, the tropospheric $f$ SOA-sv and bbSOA-sv burdens increase by 14 and $39 \%$, respectively. Nevertheless, the absence of IVOC emissions, and thus the significant decrease in anthropogenic organic compound emissions, results in a decrease in the total OA tropospheric burden by $23 \%$. This result emphasizes the importance of the volatility distributions used in the simulation and the contribution of IVOC emissions to SOA formation on a global scale.

The simulated POA in the reference model configuration is very close to the average HOA concentrations derived from the AMS measurements (Table 3). Therefore, assuming lower volatility of the organic emissions results in overprediction $(\mathrm{NMB}=43 \%)$. However, the performance of the model is significantly improved during winter (Fig. 8), since POA concentrations during that season were underpredicted (NMB $=-37 \%$; Tsimpidi et al., 2016). On the other hand, during spring the overestimate of POA increases in the sensitivity simulation $(\mathrm{NMB}=86 \%$ ) compared to the reference simulation $(\mathrm{NMB}=26 \%)$. For summer and autumn, the performance of the model changes from a slight underestimation of POA in the reference simulation $(\mathrm{NMB}=-15 \%)$ to a slight overprediction in the sensitivity test $(\mathrm{NMB}=30 \%)$. The performance of the model in reproducing the OOA concentrations worsens in this sensitivity simulation (Table 4). OOA was underpredicted by the model reference simulation ( $\mathrm{NMB}=-31 \%)$; therefore, neglecting SOA formation from IVOC emissions in the sensitivity run results in an even larger $\mathrm{OOA}$ underestimation ( $\mathrm{NMB}=-52 \%$ ). The performance of the model does not change significantly during winter (Fig. 8) since the simulated SOA formation during this season is low (Tsimpidi et al., 2016). The highest change in model performance occurs during spring when SOA is pre- dicted to reach the annual maximum (Tsimpidi et al., 2016); the predicted underestimation of OOA increases from $20 \%$ in the reference simulation to $50 \%$ in the sensitivity simulation. These results indicate that the omission of IVOCs as a source of SOA in atmospheric models can result in a significant underestimation of OA concentrations, especially during periods where formation of SOA is strong.

\subsection{High IVOCs}

In the second sensitivity simulation, the increased IVOC emissions result in an increase in total organics by $60 \%$ and $150 \%$ from anthropogenic and open biomass burning sources, respectively (Table 1). These additional organic emissions are distributed only in the intermediate-volatility bins; therefore, their impact on the simulated POA and SOAsv levels is marginal (Figs. $4 \mathrm{~b}$ and $5 \mathrm{~b}$, respectively). POA increases up to $0.6 \mu \mathrm{g} \mathrm{m}^{-3}$ over eastern China, while SOA-sv decreases up to $0.3 \mu \mathrm{g} \mathrm{m}^{-3}$ over the Congo Basin. This effect can be explained by the assumption that SOA-sv and SOAiv form a pseudo-ideal solution. As a result, the increased SOA-iv concentrations calculated in the sensitivity simulation favor the partitioning of the fresh SVOCs into the aerosol phase, forming additional POA. At the same time, SVOCs decrease in the gas phase and therefore the formation of SOA-sv is reduced in the sensitivity simulation. As expected, the largest effect is found for SOA-iv (Fig. 6b). The significant increase in IVOC emissions results in large changes of SOA-iv over areas close to anthropogenic sources (up to $5.7 \mu \mathrm{g} \mathrm{m}^{-3}$ over the IGP) and biomass burning regions (up to $5.3 \mu \mathrm{g} \mathrm{m}^{-3}$ over the Congo Basin). The increase in SOA-iv dominates the effect on total OA concentrations that increase up to $6 \mu \mathrm{g} \mathrm{m}^{-3}$ (Fig. 7b). Overall, the predicted changes of the tropospheric burden of POA and SOA-sv are small (Table 2). However, the tropospheric burdens of $f$ SOA-iv and bbSOA-iv increase by 88 and $115 \%$, respectively, resulting in an increase in the total OA burden by $38 \%$.

The additional IVOC emissions assumed in this sensitivity test do not affect the performance of the model for POA. On the other hand, these additional emissions bring the predicted SOA concentrations closer to the measured OOA levels (Table 4; Fig. 8). The NMB improves from $-31 \%$ in the reference simulation to $-10 \%$. With the exception of winter, where the model still underpredicts OOA levels $\left(\mathrm{MB}=2.2 \mu \mathrm{g} \mathrm{m}^{-3}\right.$, Fig. 8), the performance of the model for SOA improves, with seasonal NMB ranging from -16 (during summer) to $11 \%$ (during spring), compared to -33 and $-20 \%$ for the reference model, respectively. The improved performance of the model due to the increase in IVOC emissions supports the hypothesis that the IVOC emissions may have been underestimated in previous modeling studies that assumed IVOC / POA $=1.5$ (Ots et al., 2016). 
(a) Low volatility

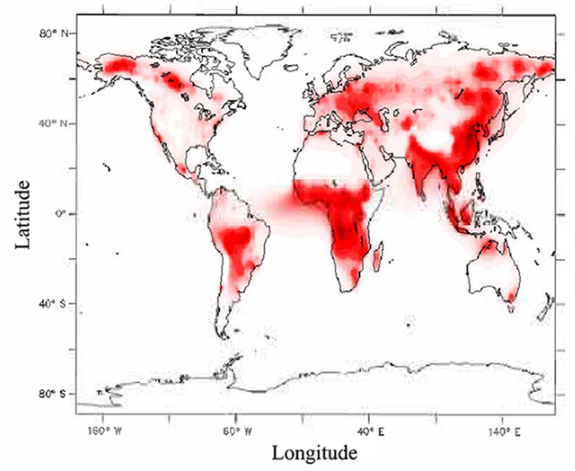

(c) Alternative POA emissions

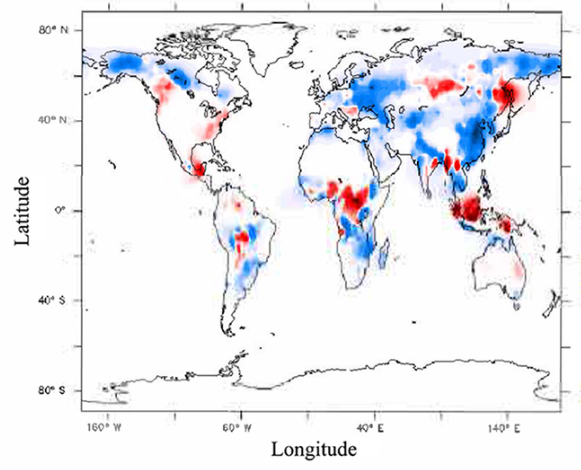

(e) Alternative aging scheme

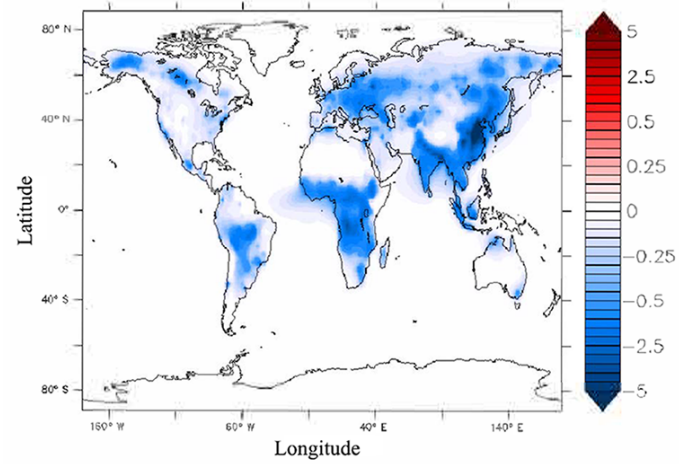

(g) Low solubility

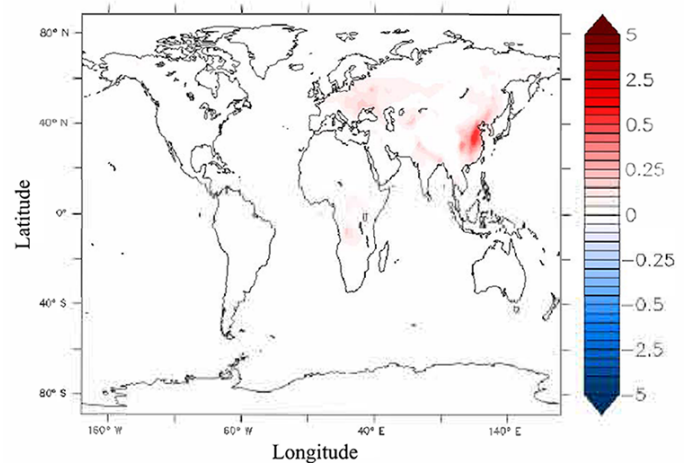

(b) High IVOCs

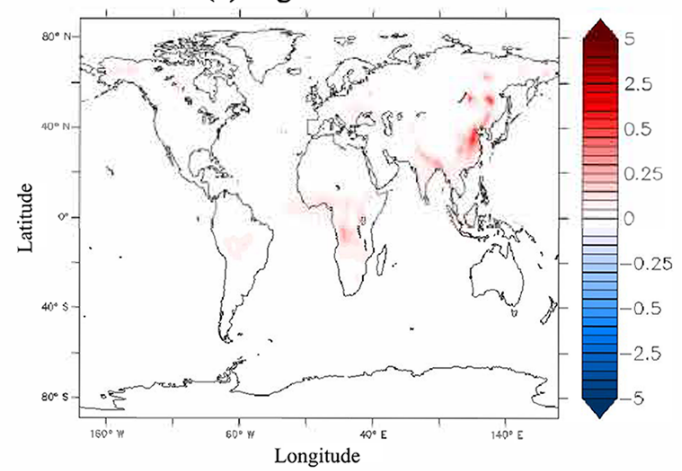

(d) High reaction rate constant

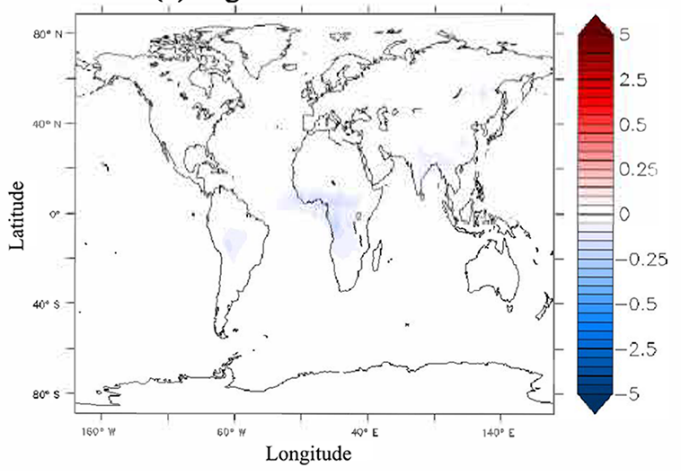

(f) Hybrid aging scheme

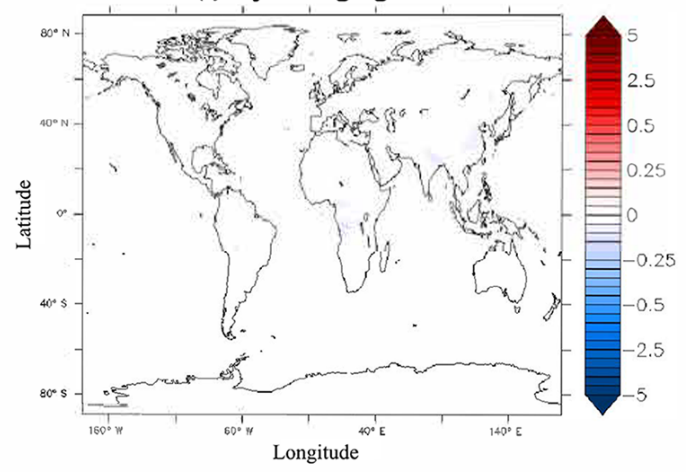

(h) Variable solubility

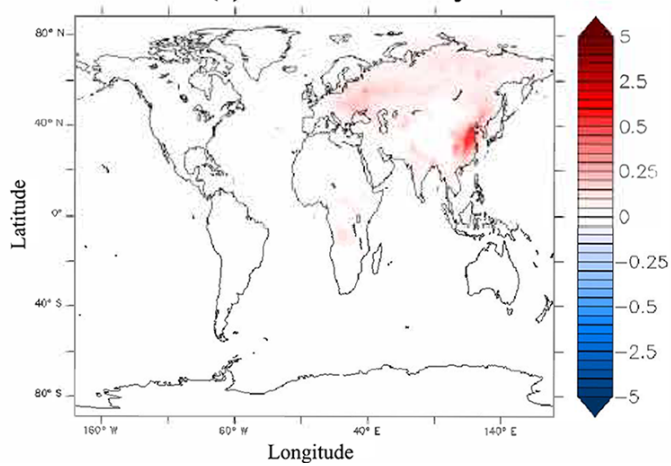

Figure 4. Absolute changes (in $\mu \mathrm{g} \mathrm{m}^{-3}$ ) of the average surface POA concentrations between the reference and the (a) low-volatility, (b) high IVOCs, (c) alternative POA emissions, (d) high reaction rate constant, (e) alternative aging scheme, (f) hybrid aging scheme, (g) lowsolubility, and (h) variable solubility simulations during the period 2001-2010. A positive change indicates an increase in the sensitivity test. 
(a) Low volatility

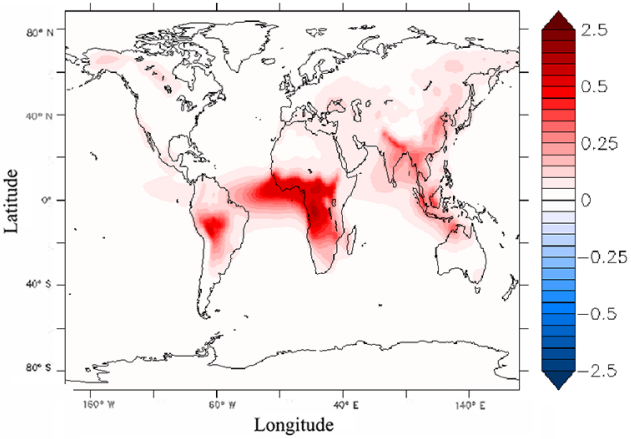

(c) Alternative POA emissions

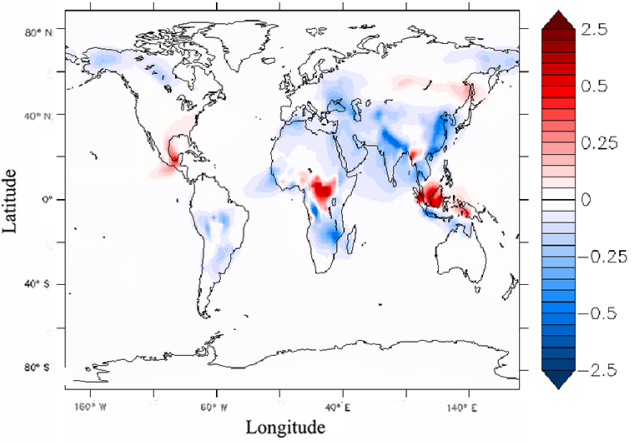

(e) Alternative aging scheme

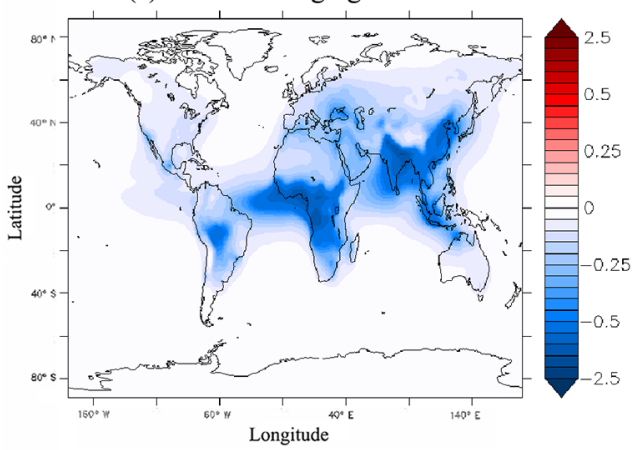

(g) Low solubility

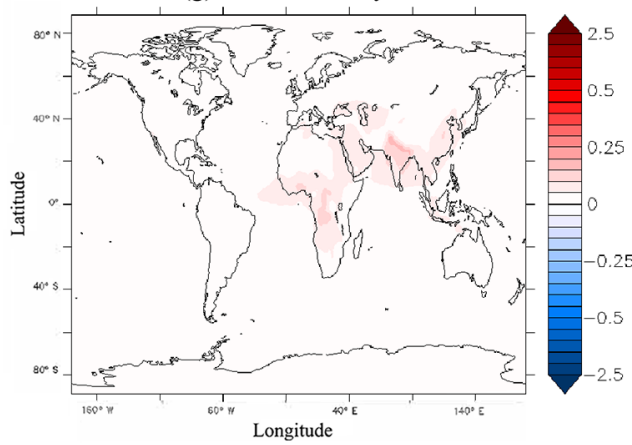

(b) High IVOCs

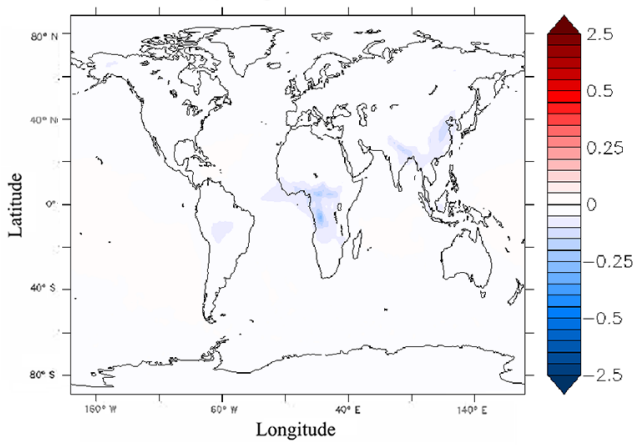

(d) High reaction rate constant

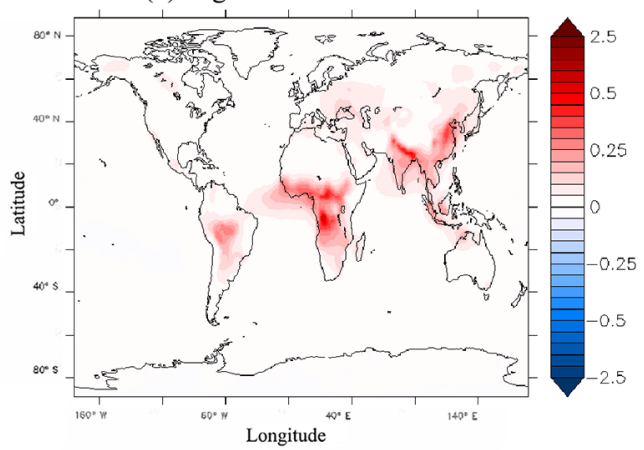

(f) Hybrid aging scheme

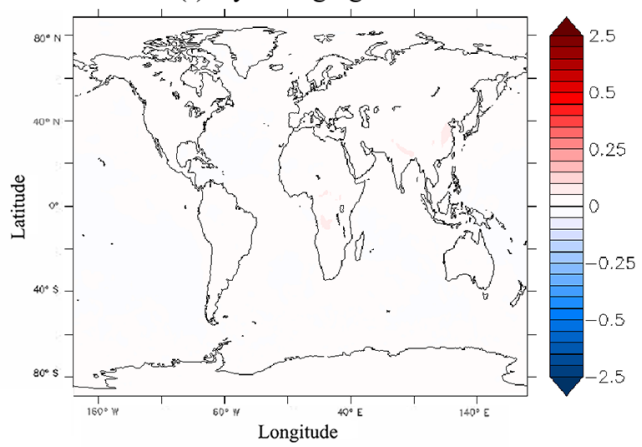

(h) Variable solubility

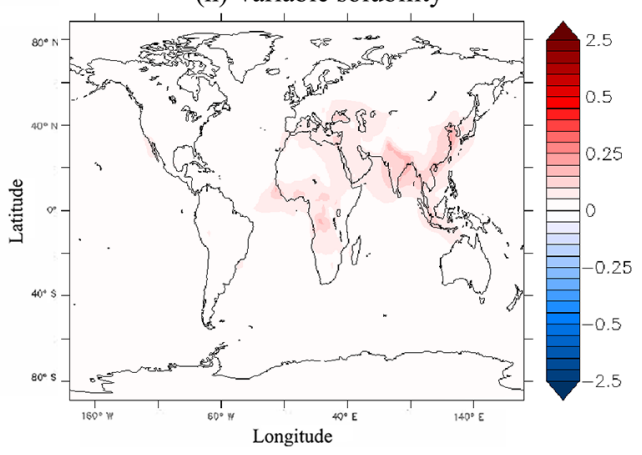

Figure 5. Absolute changes (in $\mu \mathrm{g} \mathrm{m}^{-3}$ ) of the average surface SOA concentrations from SVOCs (SOA-sv) between the reference and the (a) low-volatility, (b) high IVOCs, (c) alternative POA emissions, (d) high reaction rate constant, (e) alternative aging scheme, (f) hybrid aging scheme, (g) low-solubility, and (h) variable solubility simulations during the period 2001-2010. A positive change indicates an increase in the sensitivity test. 
(a) Low volatility

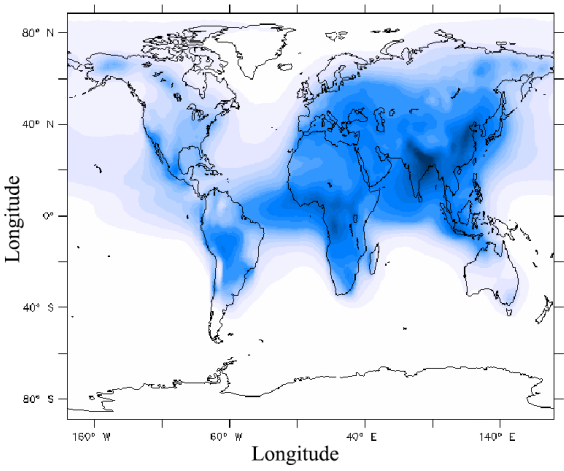

(c) Alternative POA emissions

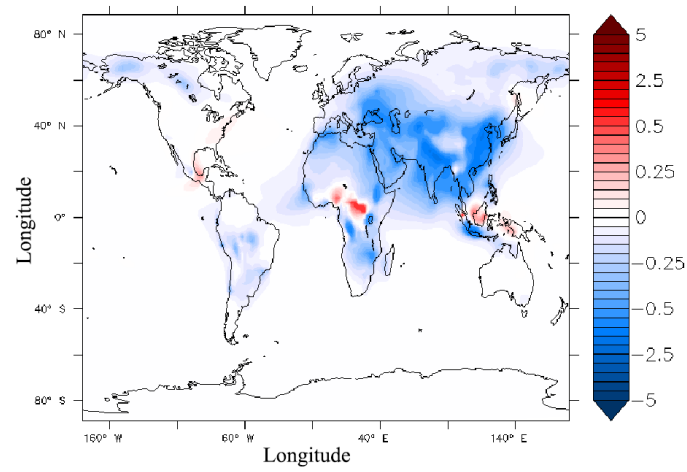

(e) Alternative aging scheme

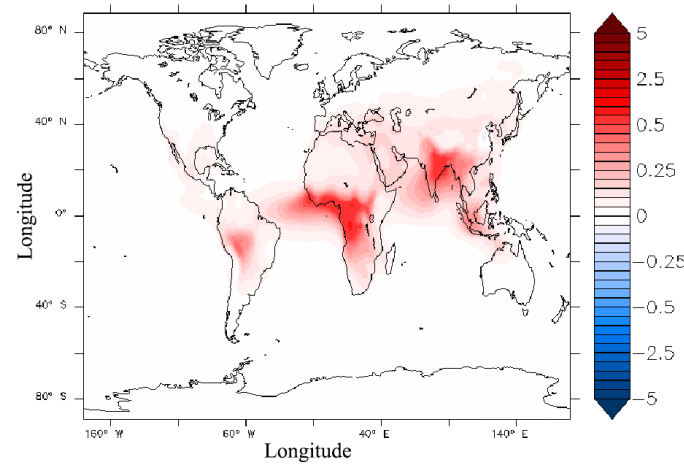

(g) Low solubility

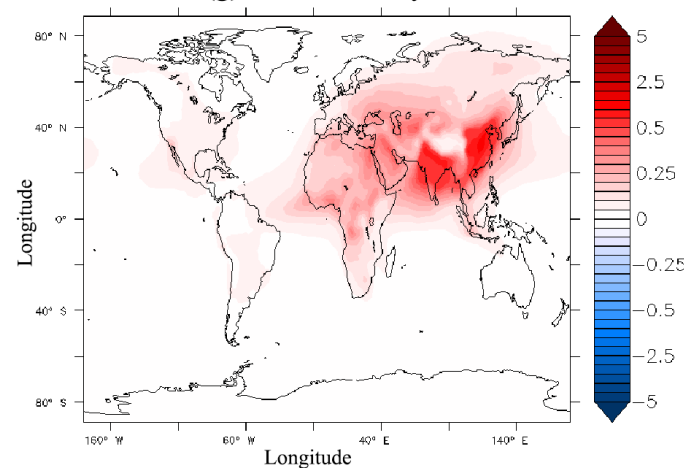

(b) High IVOCs

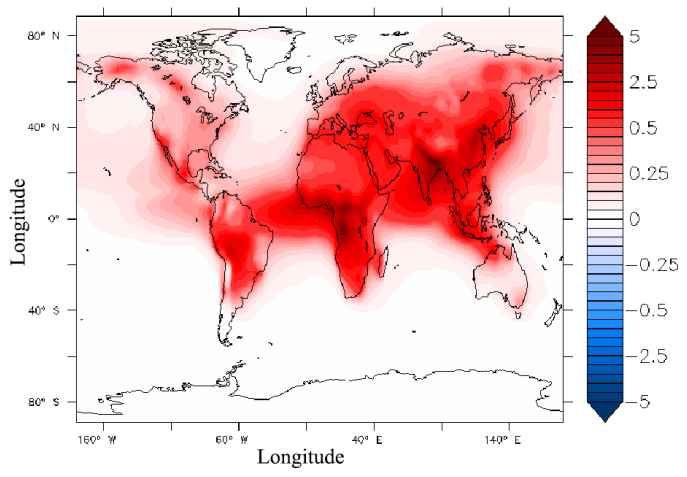

(d) High reaction rate constant

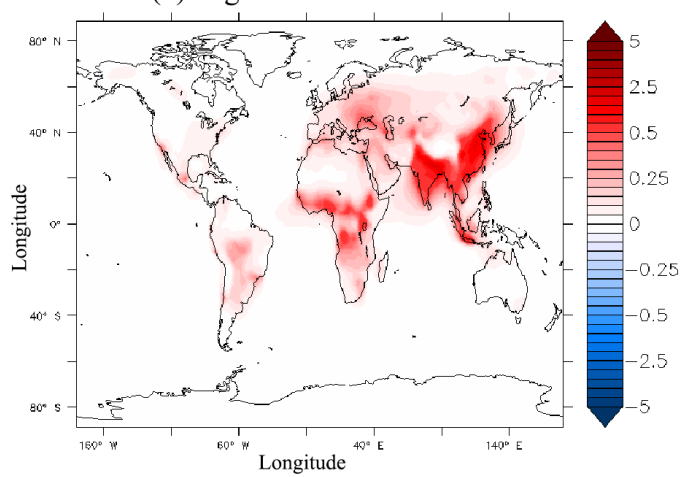

(f) Hybrid aging scheme

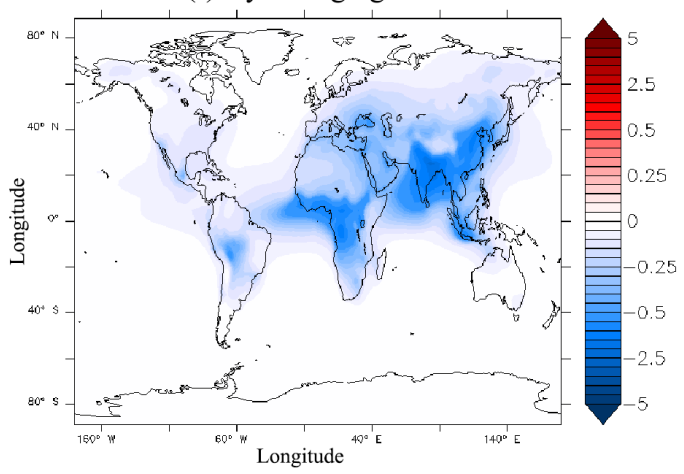

(h) Variable solubility

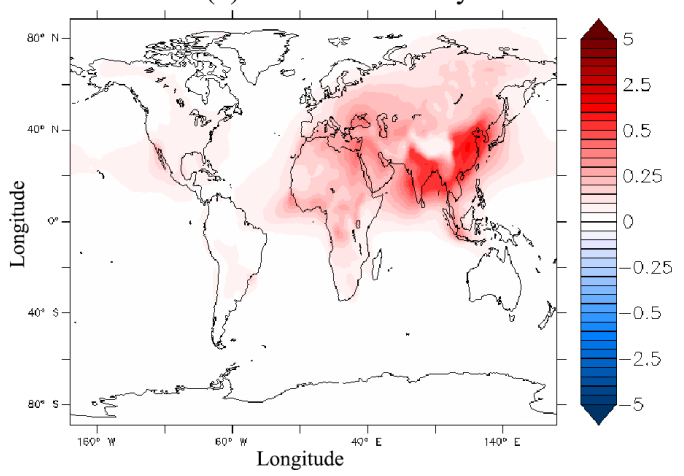

Figure 6. Absolute changes (in $\mu \mathrm{g} \mathrm{m}^{-3}$ ) of the average surface SOA concentrations from IVOCs (SOA-iv) between the reference and the (a) low-volatility, (b) high IVOCs, (c) alternative POA emissions, (d) high reaction rate constant, (e) alternative aging scheme, (f) hybrid aging scheme, (g) low-solubility, and (h) variable solubility simulations during the period 2001-2010. A positive change indicates an increase in the sensitivity test. 
(a) Low volatility

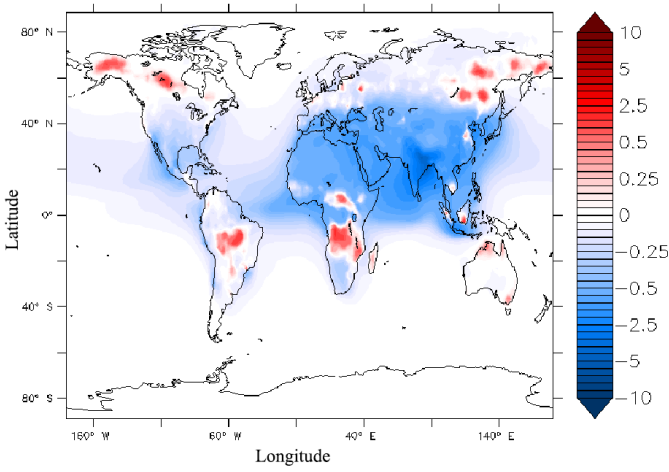

(c) Alternative POA emissions

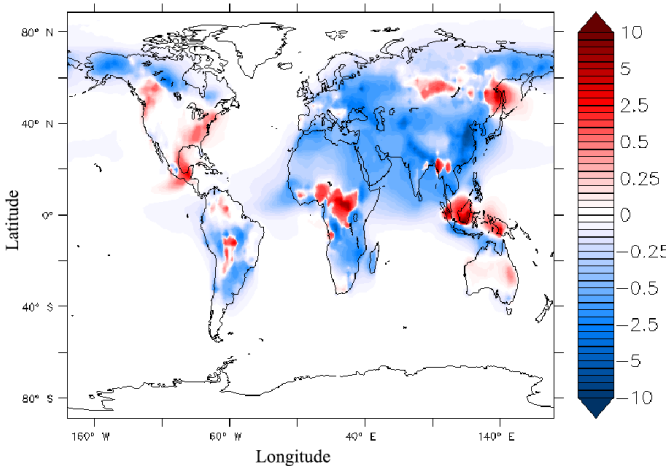

(e) Alternative aging scheme

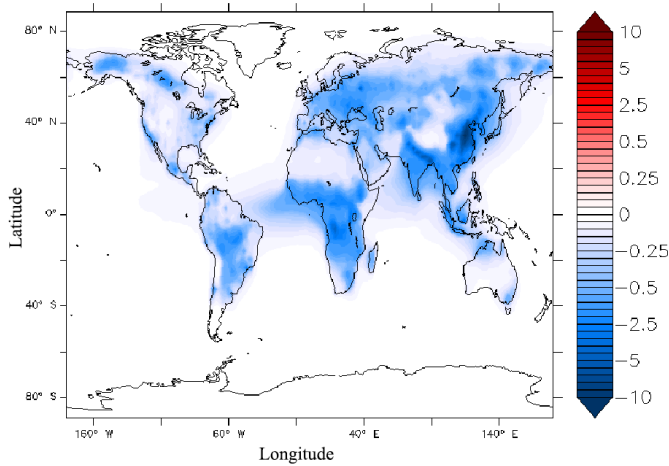

(g) Low solubility

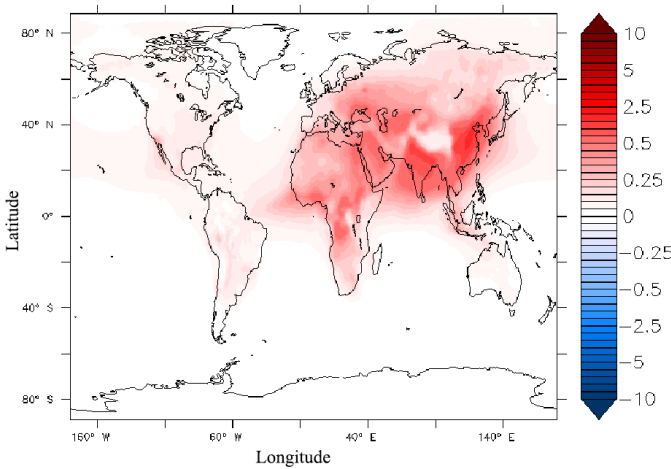

(b) High IVOCs

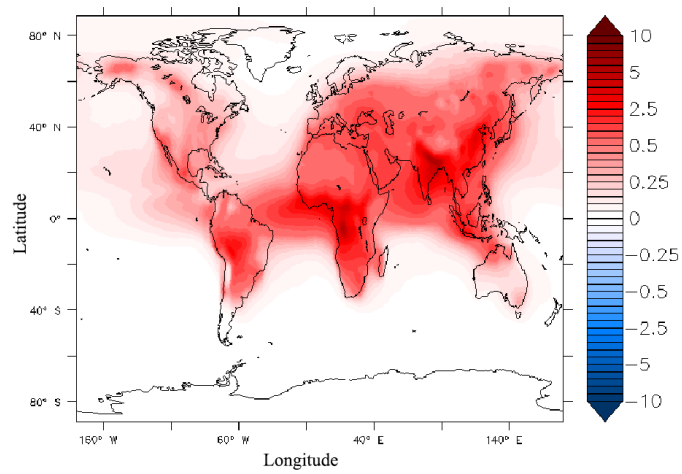

(d) High reaction rate constant

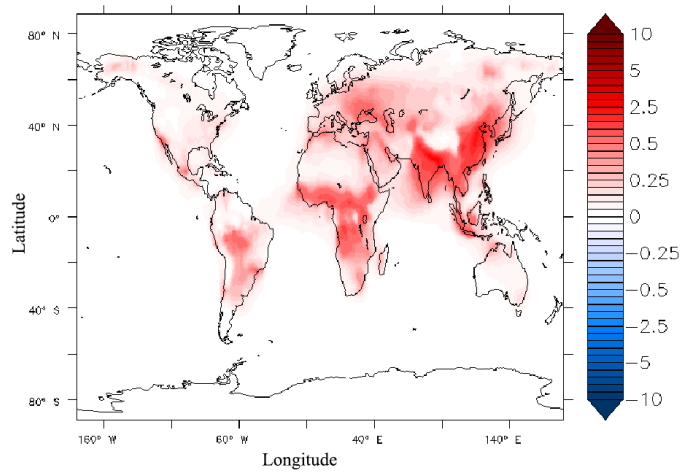

(f) Hybrid aging scheme

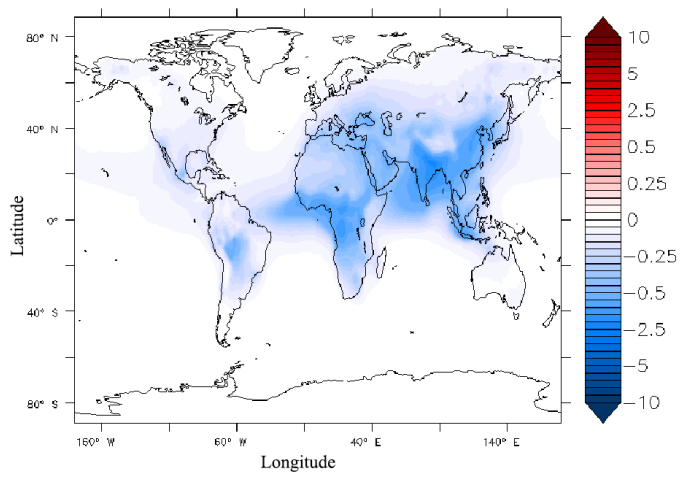

(h) Variable solubility

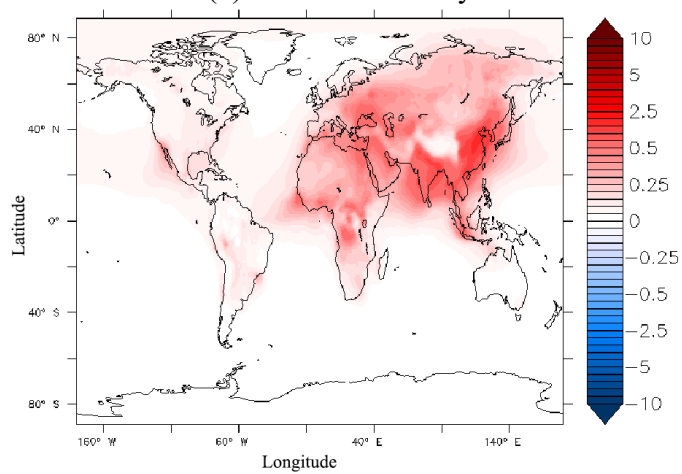

Figure 7. Absolute changes (in $\mu \mathrm{g} \mathrm{m}^{-3}$ ) of the average surface total OA concentrations between the reference and the (a) low-volatility, (b) high IVOCs, (c) alternative POA emissions, (d) high reaction rate constant, (e) alternative aging scheme, (f) hybrid aging scheme, (g) low-solubility, and (h) variable solubility simulations during the period 2001-2010. A positive change indicates an increase in the sensitivity test. 

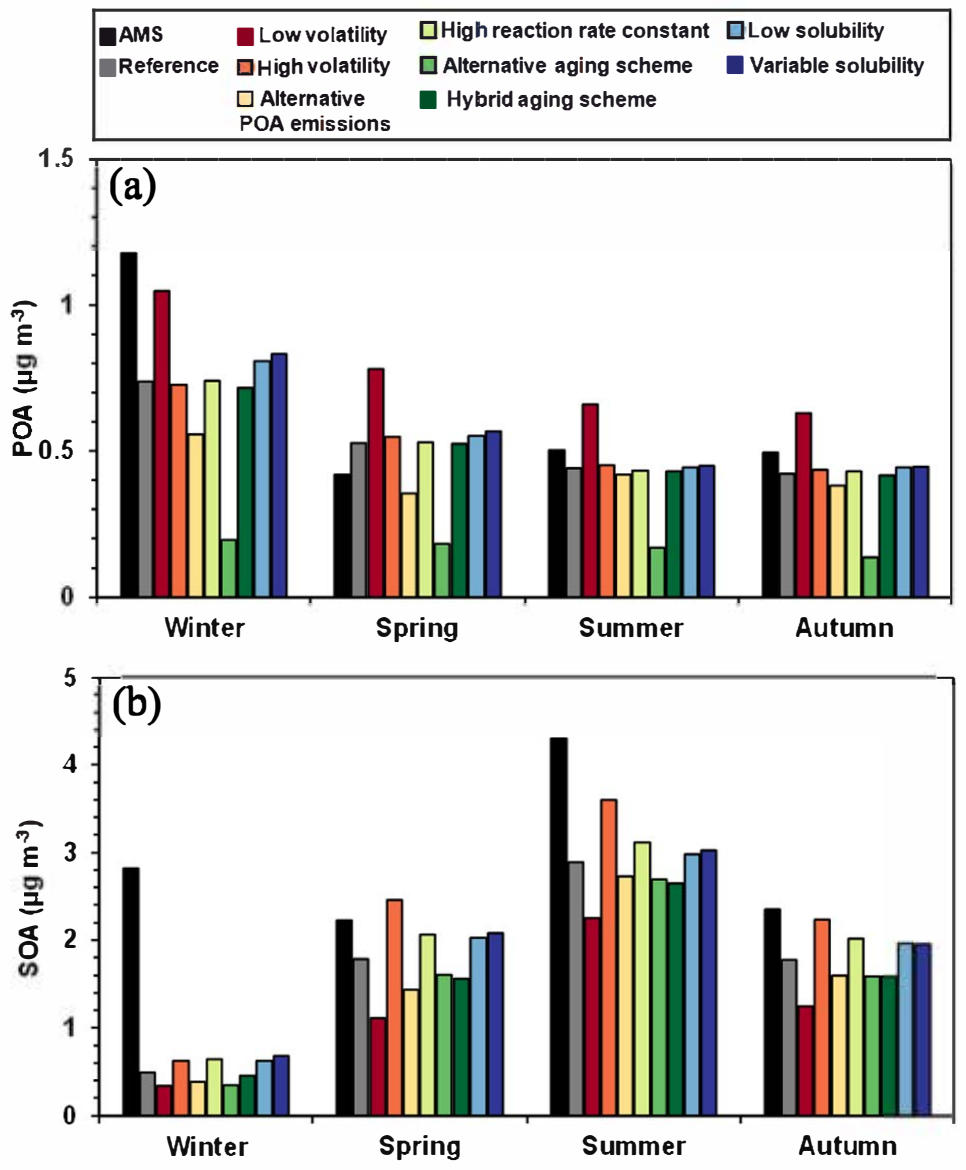

Figure 8. Average (a) POA and (b) SOA concentrations (in $\mu \mathrm{g} \mathrm{m}^{-3}$ ) measured and predicted in the reference and sensitivity simulations during winter, spring, summer, and autumn in urban-downwind and rural areas of the continental Northern Hemisphere.

\subsection{Alternative POA emissions}

The final emission sensitivity test is used to estimate the uncertainty introduced by the choice of emission database. The inventories used in the sensitivity simulation assume $36 \%$ lower fuel combustion OA emissions and $33 \%$ higher biomass burning OA emissions compared to the reference simulation, while the total OA emissions are only reduced by $9 \%$. Since the volatility distribution of the emissions is identical to the reference simulation, the fractional changes of the calculated POA, SOA-sv, and SOA-iv are also similar (Table 4). The tropospheric burden of $f \mathrm{OA}$ (the sum of $f \mathrm{POA}$, $f$ SOA-sv, and $f$ SOA-iv) decreases by $34 \%$. On the other hand, bbOA (the sum of bbPOA, bbSOA-sv, and bbSOA-iv) increases by $11 \%$. Overall, the total tropospheric OA burden increases by only $4 \%$. The changes in $f \mathrm{OA}$ and bbOA concentrations, however, are not spatially uniform. Over Europe, $f \mathrm{OA}$ decreases everywhere, up to $3.3 \mu \mathrm{g} \mathrm{m}^{-3}$, except in Paris where $f \mathrm{OA}$ increases by $0.24 \mu \mathrm{g} \mathrm{m}^{-3}$. Over the US $f$ OA slightly increases (mostly over the northeast by up to $0.6 \mu \mathrm{g} \mathrm{m}^{-3}$ ), while it decreases over Mexico by as much as $1.7 \mu \mathrm{g} \mathrm{m}^{-3}$. The largest $f \mathrm{OA}$ change is predicted over Asia, where $f$ OA decreases significantly, up to $8.3 \mu \mathrm{g} \mathrm{m}^{-3}$, mostly over East Asia and the IGP. Here, bbOA decreases over the boreal forests (up to $3.6 \mu \mathrm{g} \mathrm{m}^{-3}$ ), while it increases significantly over the Southeast Asia tropical forests by up to $14 \mu \mathrm{g}$ $\mathrm{m}^{-3}$. Over the Amazon and Congo forests, bbOA concentrations change significantly (the bbOA changes vary from -2.4 to $3.3 \mu \mathrm{g} \mathrm{m}^{-3}$ in the Amazon and from -5.3 to $7.8 \mu \mathrm{g} \mathrm{m}^{-3}$ in Congo), but the average bbOA concentration over both regions remains the same. Overall, the $f \mathrm{OA}$ and bbOA emission changes lead to total $\mathrm{OA}$ increases over the tropical and boreal forests and decreases over anthropogenic areas (Fig. 7c).

The lower OA emissions used in the sensitivity simulation (especially over China and Europe) result in a reduction of both total POA and SOA concentrations (Tables 2 and $3)$. Consequently, the model now underestimates POA with $\mathrm{NMB}=-25$ and SOA with $\mathrm{NMB}=-40 \%$. These results suggest that the use of the CMIP5 RCP4.5 emission inventory in EMAC results in OA concentrations that agree more closely with the measurements compared to the AEROCOM 
database. It also underscores the large uncertainty associated with primary OA emissions.

\section{Sensitivity to aging reactions}

\subsection{Higher aging reaction rate}

In this sensitivity simulation, the photochemical reaction rate constant for SVOCs and IVOCs has been doubled compared to the reference simulation. This results in an increase in SOA-sv and SOA-iv concentrations worldwide (Figs. 5d and 6d). SOA-sv increases, by up to $0.65 \mu \mathrm{g} \mathrm{m}^{-3}$, mostly over the tropics and the polluted regions of eastern China and the IGP (Fig. 5d). The effect on SOA-iv concentrations is even more significant, since IVOCs undergo more oxidation steps before forming SOA than SVOCs. SOA-iv increased by up to $2.4 \mu_{\mathrm{g} \mathrm{m}}^{-3}$ mostly over the IGP and eastern China (Fig. 6d). The SOA-iv increase over the tropics is smaller (up to $0.8 \mu \mathrm{g} \mathrm{m}^{-3}$ ) due to the assumed low fraction of IVOCs in biomass burning emissions. Overall, the tropospheric burdens of SOA-sv and SOA-iv both increase by $0.04 \mathrm{Tg}$ (or 11 and $7 \%$, respectively). POA is not expected to be affected directly by the change of the reaction rate constant. However, the substantial reduction of gas-phase SVOCs (due to their increased reactivity) results in the re-evaporation of POA to achieve equilibrium, reducing its concentration (Fig. 4d) mainly over the tropics (up to $0.21 \mu \mathrm{g} \mathrm{m}^{-3}$ ). This results in an overall decrease in the tropospheric POA burden by $8 \%$. Following the significant increase in both SOA-sv and SOAiv, total OA increases worldwide by up to $3 \mu \mathrm{g} \mathrm{m}^{-3}$ (Fig. 7d). Overall, the tropospheric burden of total OA increases by $4 \%$.

The model performance for POA is not affected by the change of the reaction rate constant (Table 2), since POA remains largely unchanged over the Northern Hemisphere (Fig. 4d). On the other hand, the performance of the model regarding SOA is significantly improved (Table 3). The underestimation of SOA by the model is reduced ( $\mathrm{NMB}=-22 \%)$ compared to the reference simulation (NMB $=-31 \%$ ). The best performance is found during spring $(\mathrm{NMB}=-7 \%)$ when the calculated SOA is almost unbiased. However, during winter, the model still severely underestimates SOA (NMB $=-77 \%)$, which indicates that the gas-phase oxidation of SVOCs and IVOCs does not suffice to explain the underprediction of SOA in winter.

\subsection{Alternative aging scheme}

In this sensitivity simulation we used the chemical aging scheme of Robinson et al. (2007), which is currently the most commonly used in VBS models. This aging scheme is accompanied by changes in the number of volatility bins used and the assigned emission factors, the oxidation rate constant, the volatility reductions after each oxidation step, and the increase in mass due to added oxygen (as discussed in
Sect. 3.2). The changes in the number of volatility bins and the emission factors used for the SVOCs (Fig. 2d) result in reduced condensation of SVOCs into the particulate phase during the initial partitioning and therefore in a significant decrease in POA (Fig. 4e). The decrease in POA is global and most prominent over eastern China (up to $9.3 \mu \mathrm{g} \mathrm{m}^{-3}$ ). This reflects a significant change in the tropospheric burdens of both $f$ POA and bbPOA by 65 and $38 \%$, respectively.

Furthermore, the reduced fraction of SVOCs to total OA emissions (see Sect. 3.2) results in a worldwide decrease in SOA-sv (Fig. 5e) and an increase in SOA-iv (Fig. 6e). SOAsv decreases up to $1.8 \mathrm{\mu g} \mathrm{m}^{-3}$ over the Congo Basin and the IGP. Similar to POA, the tropospheric burden of $f$ SOA-sv and bbSOA-sv decreases by 68 and $47 \%$, respectively. On the other hand, the increase in SOA-iv, due to the increase in the IVOC fraction of the emissions, is not as strong as the decrease in SOA-sv (Table 4). This is due to the slower aging in the sensitivity simulation (Fig. 1b), compared to the reference simulation (Fig. 1a), which limits the formation of SOA from IVOCs. SOA-iv increases up to $0.9 \mu \mathrm{g} \mathrm{m}^{-3}$ over the Congo Basin and the IGP, while it locally decreases by $0.1 \mu \mathrm{g} \mathrm{m}^{-3}$ over Beijing, for example. The tropospheric burden of $f$ SOA-iv and bbSOA-iv increases by 14 and $30 \%$, respectively. Overall, the sum of SOA-sv and SOA-iv decreases by $7 \%$ due to the slower aging in this sensitivity simulation. Following the simultaneous decrease in both POA and SOA, total OA decreases worldwide by up to $11 \mu \mathrm{g} \mathrm{m}{ }^{-3}$ (Fig. 7e), and its tropospheric burden is reduced by $0.2 \mathrm{Tg}$ (or $10 \%)$.

The reduction of both modeled POA and SOA results in reduced agreement of the model with AMS measurements. For POA, especially, the modeled concentrations decrease by $67 \%$ in the sensitivity simulation, resulting in a significant underprediction of AMS-HOA (NMB $=-67 \%$ ). Modeled SOA also decreases (by 10\%) in the sensitivity simulation, which degrades the model agreement with AMS-OOA measurements ( $\mathrm{NMB}=-38 \%$ ). This sensitivity test underscores the significance of the volatility distribution of the organic emissions and the associated aging scheme.

\subsection{Hybrid aging scheme}

The final chemistry sensitivity simulation focuses on the photochemical aging of IVOCs and assumptions regarding the first oxidation step. The approach used here is similar to the oxidation of the traditional VOCs, in contrast with the reference simulation where the oxidation of IVOCs produces only one product with a 2 orders of magnitude reduced volatility. However, the stoichiometric coefficient used in the reference simulation (equal to 1.15) is higher than the aerosol yields used in the sensitivity simulation (Sect. 3.2). This results in a reduction of SOA-iv concentrations by up to $2.2 \mu \mathrm{g} \mathrm{m}^{-3}$ (Fig. 6f). Since the chemical scheme for SVOCs is identical in both the reference and the sensitivity simulations, no significant change is found in either SOA-sv or POA (Figs. $5 \mathrm{f}$ 
Table 4. Percentage change of the tropospheric burden of OA components for each sensitivity simulation relative to the reference simulation during the 2001-2010 decade. Positive change corresponds to an increase. The predicted tropospheric burden in Tg of the reference simulation is also shown.

\begin{tabular}{|c|c|c|c|c|c|c|c|}
\hline \multirow{3}{*}{$\begin{array}{l}\text { Tropospheric burden } \\
\text { of reference }(\mathrm{Tg})\end{array}$} & $f$ POA & bbPOA & fSOA-sv & bbSOA-sv & $f$ SOA-iv & bbSOA-iv & Total OA \\
\hline & & & & & & & \\
\hline & \multicolumn{7}{|c|}{ Percentage change $(\%)$ from reference simulation } \\
\hline \multicolumn{8}{|l|}{ Simulation name } \\
\hline Low volatility & 53 & 48 & 14 & 39 & -100 & -100 & -23 \\
\hline High IVOCs & 7 & 5 & -3 & -4 & 88 & 165 & 38 \\
\hline Alternative & -39 & 10 & -33 & 11 & -34 & 11 & -8 \\
\hline \multicolumn{8}{|l|}{ POA emissions } \\
\hline $\begin{array}{l}\text { High reaction } \\
\text { rate constant }\end{array}$ & -10 & -7 & 11 & 11 & 8 & 6 & 4 \\
\hline $\begin{array}{l}\text { Alternative aging } \\
\text { scheme }\end{array}$ & -65 & -38 & -68 & -47 & 14 & 30 & -10 \\
\hline $\begin{array}{l}\text { Hybrid aging } \\
\text { scheme }\end{array}$ & -2 & -1 & 2 & 2 & -37 & -36 & -13 \\
\hline Low solubility & 6 & 1 & 11 & 4 & 21 & 8 & 8 \\
\hline Variable solubility & 9 & 2 & 14 & 5 & 22 & 7 & 8 \\
\hline
\end{tabular}

and 4f, respectively). The decrease in SOA-iv concentrations has a marginal effect on the initial partitioning of SVOC emissions, resulting in slightly less POA and more SOA-sv (by up to $0.1 \mu \mathrm{g} \mathrm{m}^{-3}$ in either case). Therefore, total OA concentrations are reduced worldwide following the decrease in SOA-iv. Overall, the tropospheric burden of SOA-iv decreases by $37 \%$ in the sensitivity simulation, resulting in a decrease in total OA by $13 \%$ (Table 4).

The simulated POA concentrations remain almost unchanged in the sensitivity simulation; therefore, similar to the reference simulation, the calculated POA is unbiased compared to measurements (Table 2). On the other hand, the lower SOA-iv concentrations calculated by the model in this sensitivity test aggravate the underestimation of OOA by the model $(\mathrm{NMB}=-39 \%)$. The decrease in modeled SOA-iv concentrations is larger during spring (13\%), and the calculated NMB for SOA deteriorates from $-20 \%$ in the reference simulation to $-30 \%$ in the sensitivity simulation.

\section{Sensitivity to wet and dry removal of organic vapors}

\subsection{Reduced Henry's law constant}

In this sensitivity test we used a Henry's law constant that is 2 orders of magnitude lower than in the reference simulation (see Sect. 3.3) for the gas-phase SVOCs and IVOCs. This change decreases their removal rate, thus increasing their lifetime and the concentrations of both POA (due to the condensation of the fresh SVOCs) and SOA (due to the condensation of the chemically aged SVOCs and IVOCs). POA increases up to $0.7 \mu \mathrm{g} \mathrm{m}^{-3}$ over eastern China (Fig. $4 \mathrm{~g}$ ) where POA concentrations are relatively high (Fig. 3b); how- ever, the increase in POA in the rest of the world is less than $0.2 \mu \mathrm{g} \mathrm{m}^{-3}$ (Fig. 4g). SOA-sv increases up to $0.2 \mu \mathrm{g} \mathrm{m}^{-3}$ mostly over the Congo Basin and the IGP (Fig. 5g). The most significant change is calculated for SOA-iv. SOA-iv is formed from gases (i.e., IVOCs) that need to go through more than two oxidation steps to be able to condense to the aerosol phase (in comparison to only one oxidation step for SVOCs). Therefore, by lowering the Henry's law constant of IVOCs we prolong the lifetime of SOA-iv precursors and their ability to undergo multiple oxidation steps and produce aerosols. This results in a significant increase in SOA-iv by up to $1.2 \mu \mathrm{g} \mathrm{m}^{-3}$ (Fig. $6 \mathrm{~g}$ ). Total OA increases by up to $2 \mu \mathrm{g} \mathrm{m}^{-3}$ due to the simultaneous increase in both POA and SOA (Fig. $7 \mathrm{~g}$ ). Overall, the tropospheric burden of SOA-iv increases by $17 \%$ and that of total OA by $8 \%$. It is also worth noting that the tropospheric burden of $f \mathrm{OA}$ (sum of $f \mathrm{POA}$, $f$ SOA-sv, and $f$ SOA-iv) increases by $18 \%$ compared to an increase of $5 \%$ of the bbOA (sum of bbPOA, bbSOA-sv, and bbSOA-iv). The above results emphasize the significance of the removal of organic vapors for the calculated OA concentrations and corroborate the importance of constraining the Henry' law constants of SVOCs and more importantly of IVOCs.

The change in the Henry's law constant of SVOCs does not affect the model performance for POA significantly. POA slightly increases (by $4 \%$ ), eliminating the already low model bias (Table 2). The SOA increase (by 12\%) in the sensitivity simulation (mainly due to the increased SOA-iv) results in reduced SOA underestimation (Table 2). In both POA and SOA cases the effect is more important during winter, when wet removal is most efficient, and lower during summer. POA increases during winter by $10 \%$ while 
during summer it remains unchanged. SOA increases during winter by $26 \%$ and during summer by only $3 \%$, with spring and autumn in between $(\sim 12 \%)$. Despite the wintertime POA and SOA increase in this sensitivity simulation, the model still underestimates POA $(\mathrm{NMB}=-31 \%)$ and SOA $(\mathrm{NMB}=-78 \%)$ during this season (Fig. 8).

\subsection{Different Henry's law constant for POA and SOA}

In the last sensitivity test we assume that the freshly emitted SVOCs and IVOCs are hydrophobic (with the Henry's law constant $H$ being 4 orders of magnitude lower than the reference), while after photochemical aging $H$ increases to match the value used in the reference simulation (see Sect. 3.3). POA increases up to $0.7 \mu \mathrm{g} \mathrm{m}^{-3}$, mostly over eastern China and to a lesser degree over eastern Europe and Russia (Fig. 4h). SOA-sv increases up to $0.2 \mu \mathrm{g} \mathrm{m}^{-3}$, mostly over the tropical forests of Central Africa and southeastern Asia as well as over eastern China and the IGP (Fig. 5h). SOA-iv also increases by up to $1 \mu \mathrm{g} \mathrm{m}^{-3} \mu$ (Fig. $6 \mathrm{~h}$ ) because fresh IVOCs are more hydrophobic in the sensitivity simulation; therefore, the time available to react with $\mathrm{OH}$ is extended, forming additional SOA-iv. Total OA concentrations increase by up to $2 \mu \mathrm{g} \mathrm{m}^{-3}$ over eastern China (Fig. 7h). The tropospheric burden of total OA increases by $8 \%$ in this sensitivity test with the strongest increase coming from $f$ SOA-iv $(21 \%)$.

Both the predicted POA and SOA increase in the sensitivity simulation by 6 and $12 \%$, respectively. This results in a small overprediction of POA (NMB $=4 \%)$, compared to a small underprediction in the reference simulation $(\mathrm{NMB}=-3 \%)$. For SOA, NMB improves in the sensitivity simulation $(\mathrm{NMB}=-23 \%)$ compared to the reference simulation $(-31 \%)$. Similar to the previous sensitivity test (Sect. 7.1), the effect is more relevant during winter (POA and SOA increase by 9 and $36 \%$, respectively), followed by spring (POA and SOA increase by 8 and $16 \%$, respectively) and autumn (POA and SOA increase by 7 and $10 \%$, respectively), and is small during summer (POA and SOA increase by 2 and $5 \%$, respectively; Figs. 8). This results in an improved model performance for both POA and SOA during all seasons. The highest improvement is found for SOA during spring when the NMB is reduced to $-6 \%$ from $-20 \%$ in the reference simulation. Despite the significant increase in SOA concentrations during winter (by 36\%), the model still strongly underestimates SOA $(\mathrm{NMB}=-76 \%)$, indicating that the model underprediction of OOA cannot be attributed solely to errors in the simulation of removal processes. Therefore, we expect that the discrepancy in this season is related to sources that are missing or underestimated in emission inventories (e.g., residential wood combustion in winter, Denier van der Gon et al., 2015), to additional oxidation pathways (e.g., aqueous-phase and heterogeneous oxidation reactions), and to uncertainties in SOA yields due to wall losses in laboratory chambers.

\section{Summary and conclusions}

We investigated the effect of parameters and assumptions that control the emissions, photochemical aging, and scavenging efficiency of LVOCs, SVOCs, and IVOCs on the simulated OA concentrations. We used the organic aerosol module ORACLE, based on the VBS framework, in the EMAC global chemistry-climate model. A global dataset of AMS measurements has been used to evaluate the predicted POA and SOA concentrations, based on a number of sensitivity tests.

The results show that total OA concentrations are sensitive to the emissions of IVOCs. By neglecting these emissions, the model produces unrealistically low SOA concentrations, resulting in the poorest model performance $(\mathrm{NMB}=-52 \%)$ compared to the other eight simulations conducted (Table 3 ). Conversely, increasing the IVOC emissions substantially improved the SOA model results, leading to the best model performance $(\mathrm{NMB}=-10 \%)$. These results emphasize the need to accurately estimate the IVOC emissions independently. The use of a more accurate POA emission inventory is found to be of prime importance for the model performance, especially to improve simulated POA concentrations in winter. In our tests, using an alternative POA emission inventory led to an NMB of $-25 \%$ compared to a low bias in the performance of the reference model.

Sensitivity tests of the photochemical aging of SVOCs and IVOCs indicate the importance of the $\mathrm{OH}$-reaction rate. Assuming an increased reactivity of SVOCs and IVOCs with $\mathrm{OH}$ improves the model results for SOA $(\mathrm{NMB}=-22 \%)$. This is even more important for the IVOCs, which participate in a larger number of photochemical reactions during atmospheric transport compared to the SVOCs. Another assumption tested is that oxidation reactions of IVOCs are similar to many other VOCs and produce partly oxidized compounds with several orders of magnitude lower volatilities. Despite the strong volatility reduction of the IVOC oxidation products, the performance of the model was similar to the reference simulation, since the IVOC aerosol yields were lower compared to the stoichiometric coefficient used in the reference simulation. The use of an alternative aging scheme (based on Robinson et al., 2007) resulted in lower SOA concentrations, since the photochemical aging of SVOCs and IVOCs was less effective. This led to a slight reduction in model performance for SOA (Table 3). In this sensitivity test the fraction of SVOCs to total OA emissions was lower compared to the reference simulation, resulting in a significant reduction of POA and reduced model performance $(\mathrm{NMB}=-67 \%)$. This underscores the significance of the assumed volatility distribution of OA emissions.

The calculated OA concentrations are highly sensitive to the scavenging efficiency of the gas-phase SVOCs and IVOCs, expressed by the Henry's law constant $(H)$. Reducing $H$ resulted in an increase in both POA and SOA concentrations, especially from the oxidation of IVOCs. This increase yielded improved model performance, particularly for 
SOA (Table 3). Assuming different hygroscopicity for the freshly emitted and the photochemically processed SVOCs and IVOCs resulted in a similar improvement of the model results (Tables 2 and 3 ). In this sensitivity test, the simulated POA improved substantially during winter $(\mathrm{NMB}=-29 \%)$, during which the model has difficulties reproducing AMS observations (Tsimpidi et al., 2016). Nevertheless, SOA was still underpredicted during winter $(\mathrm{NMB}=-76 \%)$, indicating that other processes (e.g., seasonally dependent residential wood combustion emissions, aqueous-phase oxidation paths, uncertainties in SOA yields due to wall losses in chambers) are a main cause of the inadequate performance.

Our results indicate that IVOCs can be major contributors to OA formation on a global scale. However, their abundance and physicochemical properties are poorly known, and more research is needed to determine the parameters that control their emissions, chemistry, and atmospheric removal. According to the model results, a combination of increased IVOC emissions, enhanced photochemical aging of IVOCs, and decreased hygroscopicity of the freshly emitted IVOCs can help reduce discrepancies between simulated SOA and observed OOA concentrations.

Data availability. The data in the study are available from the authors upon request (a.tsimpidi@mpic.de).

Competing interests. The authors declare that they have no conflict of interest.

Acknowledgements. A. P. Tsimpidi acknowledges support from a DFG individual grand programme (project reference TS 335/2-1), and V. A. Karydis acknowledges support from an FP7 Marie Curie Career Integration Grant (project reference 618349).

The article processing charges for this open-access publication were covered by the Max Planck Society.

Edited by: M. C. Facchini

Reviewed by: two anonymous referees

\section{References}

Aiken, A. C., Decarlo, P. F., Kroll, J. H., Worsnop, D. R., Huffman, J. A., Docherty, K. S., Ulbrich, I. M., Mohr, C., Kimmel, J. R., Sueper, D., Sun, Y., Zhang, Q., Trimborn, A., Northway, M., Ziemann, P. J., Canagaratna, M. R., Onasch, T. B., Alfarra, M. R., Prevot, A. S. H., Dommen, J., Duplissy, J., Metzger, A., Baltensperger, U., and Jimenez, J. L.: O / C and OM / OC ratios of primary, secondary, and ambient organic aerosols with high-resolution time-of-flight aerosol mass spectrometry, Environmen. Sci. Tech., 42, 4478-4485, 2008.

Athanasopoulou, E., Vogel, H., Vogel, B., Tsimpidi, A. P., Pandis, S. N., Knote, C., and Fountoukis, C.: Modeling the meteoro- logical and chemical effects of secondary organic aerosols during an EUCAARI campaign, Atmos. Chem. Phys., 13, 625-645, https://doi.org/10.5194/acp-13-625-2013, 2013.

Atkinson, R. and Arey, J.: Atmospheric degradation of volatile organic compounds, Chem. Rev., 103, 4605-4638, 2003.

Bergstrom, R., van der Gon, H. A. C. D., Prevot, A. S. H., Yttri, K. E., and Simpson, D.: Modelling of organic aerosols over Europe (2002-2007) using a volatility basis set (VBS) framework: application of different assumptions regarding the formation of secondary organic aerosol, Atmos. Chem. Phys., 12, 8499-8527, https://doi.org/10.5194/acp-12-8499-2012, 2012.

Canagaratna, M. R., Jimenez, J. L., Kroll, J. H., Chen, Q., Kessler, S. H., Massoli, P., Ruiz, L. H., Fortner, E., Williams, L. R., Wilson, K. R., Surratt, J. D., Donahue, N. M., Jayne, J. T., and Worsnop, D. R.: Elemental ratio measurements of organic compounds using aerosol mass spectrometry: characterization, improved calibration, and implications, Atmos. Chem. Phys., 15, 253-272, https://doi.org/10.5194/acp-15-253-2015, 2015.

Chacon-Madrid, H. J., Henry, K. M., and Donahue, N. M.: Photooxidation of pinonaldehyde at low $\mathrm{NO}_{x}$ : from chemistry to organic aerosol formation, Atmos. Chem. Phys., 13, 3227-3236, https://doi.org/10.5194/acp-13-3227-2013, 2013.

Clarke, L., Edmonds, J., Jacoby, H., Pitcher, H., Reilly, J., and Richels, R.: Scenarios of greenhouse gas emissions and atmospheric concentrations (Part A) and review of integrated scenario development and application (Part B), A report by the U.S. climate change science program and the subcommittee on global change research, Department of Energy, Office of Biological \& Environmental Research, Washington, DC, USA, 2007.

Donahue, N. M., Robinson, A. L., Stanier, C. O., and Pandis, S. N.: Coupled partitioning, dilution, and chemical aging of semivolatile organics, Environ. Sci. Technol., 40, 2635-2643, 2006.

Fountoukis, C., Racherla, P. N., Denier van der Gon, H. A. C., Polymeneas, P., Charalampidis, P. E., Pilinis, C., Wiedensohler, A., Dall'Osto, M., O'Dowd, C., and Pandis, S. N.: Evaluation of a three-dimensional chemical transport model (PMCAMx) in the European domain during the EUCAARI May 2008 campaign, Atmos. Chem. Phys., 11, 10331-10347, https://doi.org/10.5194/acp-11-10331-2011, 2011.

Fountoukis, C., Megaritis, A. G., Skyllakou, K., Charalampidis, P. E., Pilinis, C., Denier van der Gon, H. A. C., Crippa, M., Canonaco, F., Mohr, C., Prévôt, A. S. H., Allan, J. D., Poulain, L., Petäjä, T., Tiitta, P., Carbone, S., Kiendler-Scharr, A., Nemitz, E., O'Dowd, C., Swietlicki, E., and Pandis, S. N.: Organic aerosol concentration and composition over Europe: insights from comparison of regional model predictions with aerosol mass spectrometer factor analysis, Atmos. Chem. Phys., 14, 9061-9076, https://doi.org/10.5194/acp-14-9061-2014, 2014.

Grieshop, A. P., Logue, J. M., Donahue, N. M., and Robinson, A. L.: Laboratory investigation of photochemical oxidation of organic aerosol from wood fires 1: measurement and simulation of organic aerosol evolution, Atmos. Chem. Phys., 9, 1263-1277, https://doi.org/10.5194/acp-9-1263-2009, 2009.

Hodzic, A., Jimenez, J. L., Madronich, S., Canagaratna, M. R., DeCarlo, P. F., Kleinman, L., and Fast, J.: Modeling organic aerosols in a megacity: potential contribution of semi-volatile and intermediate volatility primary organic compounds to secondary or- 
ganic aerosol formation, Atmos. Chem. Phys., 10, 5491-5514, https://doi.org/10.5194/acp-10-5491-2010, 2010.

Hodzic, A., Aumont, B., Knote, C., Lee-Taylor, J., Madronich, S., and Tyndall, G.: Volatility dependence of Henry's law constants of condensable organics: Application to estimate depositional loss of secondary organic aerosols, Geophys. Res. Lett., 41, 4795-4804, 2014.

Jathar, S. H., Farina, S. C., Robinson, A. L., and Adams, P. J.: The influence of semi-volatile and reactive primary emissions on the abundance and properties of global organic aerosol, Atmos. Chem. Phys., 11, 7727-7746, https://doi.org/10.5194/acp11-7727-2011, 2011.

Jathar, S. H., Miracolo, M. A., Presto, A. A., Donahue, N. M., Adams, P. J., and Robinson, A. L.: Modeling the formation and properties of traditional and non-traditional secondary organic aerosol: problem formulation and application to aircraft exhaust, Atmos. Chem. Phys., 12, 9025-9040, https://doi.org/10.5194/acp-12-9025-2012, 2012.

Jathar, S. H., Gordon, T. D., Hennigan, C. J., Pye, H. O. T., Pouliot, G., Adams, P. J., Donahue, N. M., and Robinson, A. L.: Unspeciated organic emissions from combustion sources and their influence on the secondary organic aerosol budget in the United States, P. Natl. Acad. Sci. USA, 111, 10473-10478, 2014.

Jimenez, J. L., Canagaratna, M. R., Donahue, N. M., Prevot, A. S. H., Zhang, Q., Kroll, J. H., DeCarlo, P. F., Allan, J. D., Coe, H., Ng, N. L., Aiken, A. C., Docherty, K. S., Ulbrich, I. M., Grieshop, A. P., Robinson, A. L., Duplissy, J., Smith, J. D., Wilson, K. R., Lanz, V. A., Hueglin, C., Sun, Y. L., Tian, J., Laaksonen, A., Raatikainen, T., Rautiainen, J., Vaattovaara, P., Ehn, M., Kulmala, M., Tomlinson, J. M., Collins, D. R., Cubison, M. J., Dunlea, E. J., Huffman, J. A., Onasch, T. B., Alfarra, M. R., Williams, P. I., Bower, K., Kondo, Y., Schneider, J., Drewnick, F., Borrmann, S., Weimer, S., Demerjian, K., Salcedo, D., Cottrell, L., Griffin, R., Takami, A., Miyoshi, T., Hatakeyama, S., Shimono, A., Sun, J. Y., Zhang, Y. M., Dzepina, K., Kimmel, J. R., Sueper, D., Jayne, J. T., Herndon, S. C., Trimborn, A. M., Williams, L. R., Wood, E. C., Middlebrook, A. M., Kolb, C. E., Baltensperger, U., and Worsnop, D. R.: Evolution of organic aerosols in the atmosphere, Science, 326, 1525-1529, 2009.

Jo, D. S., Park, R. J., Kim, M. J., and Spracklen, D. V.: Effects of chemical aging on global secondary organic aerosol using the volatility basis set approach, Atmos. Environ., 81, 230-244, 2013.

Jöckel, P., Tost, H., Pozzer, A., Bruehl, C., Buchholz, J., Ganzeveld, L., Hoor, P., Kerkweg, A., Lawrence, M. G., Sander, R., Steil, B., Stiller, G., Tanarhte, M., Taraborrelli, D., Van Aardenne, J., and Lelieveld, J.: The atmospheric chemistry general circulation model ECHAM5/MESSy1: consistent simulation of ozone from the surface to the mesosphere, Atmos. Chem. Phys., 6, 50675104, https://doi.org/10.5194/acp-6-5067-2006, 2006.

Kanakidou, M., Seinfeld, J. H., Pandis, S. N., Barnes, I., Dentener, F. J., Facchini, M. C., Van Dingenen, R., Ervens, B., Nenes, A., Nielsen, C. J., Swietlicki, E., Putaud, J. P., Balkanski, Y., Fuzzi, S., Horth, J., Moortgat, G. K., Winterhalter, R., Myhre, C. E. L., Tsigaridis, K., Vignati, E., Stephanou, E. G., and Wilson, J.: Organic aerosol and global climate modelling: a review, Atmos. Chem. Phys., 5, 1053-1123, https://doi.org/10.5194/acp-5-10532005, 2005.
Karydis, V. A., Tsimpidi, A. P., Pozzer, A., Astitha, M., and Lelieveld, J.: Effects of mineral dust on global atmospheric nitrate concentrations, Atmos. Chem. Phys., 16, 1491-1509, https://doi.org/10.5194/acp-16-1491-2016, 2016.

Karydis, V. A., Tsimpidi, A. P., Bacer, S., Pozzer, A., Nenes, A., and Lelieveld, J.: Global impact of mineral dust on cloud droplet number concentration, Atmos. Chem. Phys., 17, 5601-5621, https://doi.org/10.5194/acp-17-5601-2017, 2017.

Kerkweg, A., Buchholz, J., Ganzeveld, L., Pozzer, A., Tost, H., and Jöckel, P.: Technical Note: An implementation of the dry removal processes DRY DEPosition and SEDImentation in the Modular Earth Submodel System (MESSy), Atmos. Chem. Phys., 6, 4617-4632, https://doi.org/10.5194/acp-6-4617-2006, 2006a.

Kerkweg, A., Sander, R., Tost, H., and Jöckel, P.: Technical note: Implementation of prescribed (OFFLEM), calculated (ONLEM), and pseudo-emissions (TNUDGE) of chemical species in the Modular Earth Submodel System (MESSy), Atmos. Chem. Phys., 6, 3603-3609, https://doi.org/10.5194/acp-6-3603-2006, 2006b.

Kroll, J. H. and Seinfeld, J. H.: Chemistry of secondary organic aerosol: Formation and evolution of low-volatility organics in the atmosphere, Atmos. Environ., 42, 3593-3624, 2008.

Lauer, A., Eyring, V., Hendricks, J., Joeckel, P., and Lohmann, U.: Global model simulations of the impact of ocean-going ships on aerosols, clouds, and the radiation budget, Atmos. Chem. Phys., 7, 5061-5079, https://doi.org/10.5194/acp-7-5061-2007, 2007.

Li, G., Zavala, M., Lei, W., Tsimpidi, A. P., Karydis, V. A., Pandis, S. N., Canagaratna, M. R., and Molina, L. T.: Simulations of organic aerosol concentrations in Mexico City using the WRF-CHEM model during the MCMA2006/MILAGRO campaign, Atmos. Chem. Phys., 11, 37893809, https://doi.org/10.5194/acp-11-3789-2011, 2011.

May, A. A., Levin, E. J. T., Hennigan, C. J., Riipinen, I., Lee, T., Collett, J. L., Jimenez, J. L., Kreidenweis, S. M., and Robinson, A. L.: Gas-particle partitioning of primary organic aerosol emissions: 3. Biomass burning, J. Geophys. Res.-Atmos., 118, 11327-11338, 2013a.

May, A. A., Presto, A. A., Hennigan, C. J., Nguyen, N. T., Gordon, T. D., and Robinson, A. L.: Gas-particle partitioning of primary organic aerosol emissions: (1) Gasoline vehicle exhaust, Atmospheric Environment, 77, 128-139, 2013b.

May, A. A., Presto, A. A., Hennigan, C. J., Nguyen, N. T., Gordon, T. D., and Robinson, A. L.: Gas-Particle Partitioning of Primary Organic Aerosol Emissions: (2) Diesel Vehicles, Environ. Sci. Technol., 47, 8288-8296, 2013c.

Murphy, B. N. and Pandis, S. N.: Simulating the formation of semivolatile primary and secondary organic aerosol in a regional chemical transport model, Environ. Sci. Technol., 43, 47224728, 2009.

Murphy, B. N., Donahue, N. M., Fountoukis, C., Dall'Osto, M., O'Dowd, C., Kiendler-Scharr, A., and Pandis, S. N.: Functionalization and fragmentation during ambient organic aerosol aging: application of the 2-D volatility basis set to field studies, Atmos. Chem. Phys., 12, 10797-10816, https://doi.org/10.5194/acp-1210797-2012, 2012.

Ots, R., Young, D. E., Vieno, M., Xu, L., Dunmore, R. E., Allan, J. D., Coe, H., Williams, L. R., Herndon, S. C., Ng, N. L., Hamilton, J. F., Bergström, R., Di Marco, C., Nemitz, E., Mackenzie, I. A., Kuenen, J. J. P., Green, D. C., Reis, S., and 
Heal, M. R.: Simulating secondary organic aerosol from missing diesel-related intermediate-volatility organic compound emissions during the Clean Air for London (ClearfLo) campaign, Atmos. Chem. Phys., 16, 6453-6473, https://doi.org/10.5194/acp16-6453-2016, 2016.

Pozzer, A., de Meij, A., Pringle, K. J., Tost, H., Doering, U. M., van Aardenne, J., and Lelieveld, J.: Distributions and regional budgets of aerosols and their precursors simulated with the EMAC chemistry-climate model, Atmos. Chem. Phys., 12, 961-987, https://doi.org/10.5194/acp-12-961-2012, 2012.

Pringle, K. J., Tost, H., Message, S., Steil, B., Giannadaki, D., Nenes, A., Fountoukis, C., Stier, P., Vignati, E., and Lelieveld, J.: Description and evaluation of GMXe: a new aerosol submodel for global simulations (v1), Geosci. Model Dev., 3, 391-412, https://doi.org/10.5194/gmd-3-391-2010, 2010.

Pye, H. O. T. and Seinfeld, J. H.: A global perspective on aerosol from low-volatility organic compounds, Atmos. Chem. Phys., 10, 4377-4401, https://doi.org/10.5194/acp-10-4377-2010, 2010.

Robinson, A. L., Donahue, N. M., Shrivastava, M. K., Weitkamp, E. A., Sage, A. M., Grieshop, A. P., Lane, T. E., Pierce, J. R., and Pandis, S. N.: Rethinking organic aerosols: Semivolatile emissions and photochemical aging, Science, 315, 1259-1262, 2007.

Robinson, A. L., Grieshop, A. P., Donahue, N. M., and Hunt, S. W.: Updating the conceptual model for fine particle mass emissions from combustion systems, J. Air Waste Manage., 60, 1204-1222, 2010.

Sander, R., Baumgaertner, A., Gromov, S., Harder, H., Jöckel, P., Kerkweg, A., Kubistin, D., Regelin, E., Riede, H., Sandu, A., Taraborrelli, D., Tost, H., and Xie, Z.-Q.: The atmospheric chemistry box model CAABA/MECCA-3.0, Geosci. Model Dev., 4, 373-380, https://doi.org/10.5194/gmd-4-373-2011, 2011.

Shrivastava, M., Fast, J., Easter, R., Gustafson Jr., W. I., Zaveri, R. A., Jimenez, J. L., Saide, P., and Hodzic, A.: Modeling organic aerosols in a megacity: comparison of simple and complex representations of the volatility basis set approach, Atmos. Chem. Phys., 11, 6639-6662, https://doi.org/10.5194/acp11-6639-2011, 2011.

Shrivastava, M. K., Lane, T. E., Donahue, N. M., Pandis, S. N., and Robinson, A. L.: Effects of gas particle partitioning and aging of primary emissions on urban and regional organic aerosol concentrations, J. Geophys. Res.-Atmos., 113, D18301, https://doi.org/10.1029/2007JD009735, 2008.

Tost, H., Jöckel, P., Kerkweg, A., Sander, R., and Lelieveld, J.: Technical note: A new comprehensive SCAVenging submodel for global atmospheric chemistry modelling, Atmos. Chem. Phys., 6, 565-574, https://doi.org/10.5194/acp-6-565-2006, 2006.

Tsimpidi, A. P., Karydis, V. A., Zavala, M., Lei, W., Molina, L., Ulbrich, I. M., Jimenez, J. L., and Pandis, S. N.: Evaluation of the volatility basis-set approach for the simulation of organic aerosol formation in the Mexico City metropolitan area, Atmos. Chem. Phys., 10, 525-546, https://doi.org/10.5194/acp-10-5252010, 2010.
Tsimpidi, A. P., Karydis, V. A., Zavala, M., Lei, W., Bei, N., Molina, L., and Pandis, S. N.: Sources and production of organic aerosol in Mexico City: insights from the combination of a chemical transport model (PMCAMx-2008) and measurements during MILAGRO, Atmos. Chem. Phys., 11, 5153-5168, https://doi.org/10.5194/acp-11-5153-2011, 2011.

Tsimpidi, A. P., Karydis, V. A., Pozzer, A., Pandis, S. N., and Lelieveld, J.: ORACLE (v1.0): module to simulate the organic aerosol composition and evolution in the atmosphere, Geosci. Model Dev., 7, 3153-3172, https://doi.org/10.5194/gmd-7-31532014, 2014.

Tsimpidi, A. P., Karydis, V. A., Pandis, S. N., and Lelieveld, J.: Global combustion sources of organic aerosols: model comparison with 84 AMS factor-analysis data sets, Atmos. Chem. Phys., 16, 8939-8962, https://doi.org/10.5194/acp-168939-2016, 2016a.

Tsimpidi, A. P., Karydis, V. A., Pandis, S. N., and Lelieveld, J.: Global combustion sources of organic aerosols: model comparison with 84 AMS factor-analysis data sets, Atmos. Chem. Phys., 16, 8939-8962, https://doi.org/10.5194/acp-168939-2016, 2016b.

van der Werf, G. R., Randerson, J. T., Giglio, L., Collatz, G. J., Mu, M., Kasibhatla, P. S., Morton, D. C., DeFries, R. S., Jin, Y., and van Leeuwen, T. T.: Global fire emissions and the contribution of deforestation, savanna, forest, agricultural, and peat fires (1997-2009), Atmos. Chem. Phys., 10, 11707-11735, https://doi.org/10.5194/acp-10-11707-2010, 2010.

Zhang, Q., Jimenez, J. L., Canagaratna, M. R., Ulbrich, I. M., Ng, N. L., Worsnop, D. R., and Sun, Y. L.: Understanding atmospheric organic aerosols via factor analysis of aerosol mass spectrometry: a review, Anal. Bioanal. Chem., 401, 3045-3067, 2011.

Zhang, Q. J., Beekmann, M., Drewnick, F., Freutel, F., Schneider, J., Crippa, M., Prevot, A. S. H., Baltensperger, U., Poulain, L., Wiedensohler, A., Sciare, J., Gros, V., Borbon, A., Colomb, A., Michoud, V., Doussin, J. F., van der Gon, H. A. C. D., Haeffelin, M., Dupont, J. C., Siour, G., Petetin, H., Bessagnet, B., Pandis, S. N., Hodzic, A., Sanchez, O., Honore, C., and Perrussel, O.: Formation of organic aerosol in the Paris region during the MEGAPOLI summer campaign: evaluation of the volatility-basis-set approach within the CHIMERE model, Atmos. Chem. Phys., 13, 5767-5790, https://doi.org/10.5194/acp13-5767-2013, 2013.

Zhang, X., Cappa, C. D., Jathar, S. H., McVay, R. C., Ensberg, J. J., Kleeman, M. J., and Seinfeld, J. H.: Influence of vapor wall loss in laboratory chambers on yields of secondary organic aerosol, $\mathrm{P}$. Natl. Acad. USA, 111, 5802-5807, 2014. 